\title{
Consumer Behaviour with Environmental and Social Externalities: Implications for Analysis and Policy
}

\begin{abstract}
In this paper we summarise some of our recent work on consumer behaviour, drawing on recent developments in behavioural economics, particularly linked to sociology as much as psychology, in which consumers are embedded in a social context, so their behaviour is shaped by their interactions with other consumers. For the purpose of this paper we also allow consumption to cause environmental damage. Analysing the social context of consumption naturally lends itself to the use of game theoretic tools. We shall be concerned with two ways in which social interactions affect consumer preferences and behaviour: socially-embedded preferences, where the behaviour of other consumers affect an individual's preferences and hence consumption (we consider two examples: conspicuous consumption and consumption norms) and socially-directed preferences where people display altruistic behaviour. Our aim is to show that building links between sociological and behavioural economic approaches to the study of consumer behaviour can lead to significant and surprising implications for conventional economic analysis and policy prescriptions, especially with respect to environmental policy.
\end{abstract}

Key words: consumer behaviour, social context, environmental policy, game theory, competitive consumption, consumption norms, altruism, moral behaviour, Kantian calculus

JEL Codes: D1, D6, H2, Q5, Z1

January 2015 


\section{Section 1: Introduction}

Much of the economics literature on game theory and the environment has focussed on issues such as the extent of collaboration between national governments in tackling global environmental problems, for example, climate change, a literature to which Professor Alfred Endres has made significant contributions - see Endres (1997), Endres and Finus (1998, $1999,2002)$ and Endres and Ohl $(2002,2003)$ or on the interactions between firms or firms and governments, for example in the literature on trade and environment (see for example Rauscher (1997), Copeland and Taylor (2005), Ulph and Ulph (2007)). In this paper we review work which has remained a relatively neglected area by economists (in particular environmental economists), namely the behaviour in market settings of consumers with interdependent preferences ${ }^{1}$.

There are three motivations for our interest in this topic. First, in regard to global climate change, it has been estimated that if one analyses the supply chains of commodities, then some $70 \%$ of UK emissions of greenhouse gases depend on choices made by the household sector, through their purchases of goods and services, the practices which govern their use of energy for activities such as heating or washing, and the disposal of products (Gough et al. (2012)). To tackle climate change it is therefore important to understand what might influence consumer behaviour.

This brings us to our second motivation. While standard environmental economics arguments concerning the use of environmental taxes or emissions trading undoubtedly have an important role to play in changing consumer behaviour, Croson and Treich (2014) argue that the conventional economic model of consumers as rational individuals concerned solely with their own well-being does not account for many aspects of consumer behaviour. They survey a range of areas of environmental policy-making which has drawn on some of the insights from the now well-established field of behavioural economics (for excellent summaries of behavioural economics see Tirole (2002), Camerer, Lowenstein and Rabin (2004), Sobel (2005) and Bernheim and Rangel (2007); for an excellent survey of how these approaches affect the analysis of environmental issues such as climate change see IPCC (2014)). Croson and Treich note that environmental economics is a particularly apposite area for the application of ideas from behavioural economics because individuals' concerns about the environmental effects of their consumption are closely related to broader moral feelings, such as shame or guilt, and, in areas such as climate change, involve complex, global and long-term effects where bounded rationality is pertinent. Within the field of behavioural environmental economics much, though not all, of the cross-fertilisation has been between psychology and economics (for example, risk-perception and prospect theory, biases in contingent valuation, reference-dependent preferences). Like Croson and Treich we argue that it is also important to build closer links between economics, psychology and sociology by studying the behaviour of individual consumers embedded in a social context with other consumers. This provides the second motivation for this paper and explains why we study market environments. In tackling this issue we do not challenge the basic economic assumption that individual consumers are rational (in the sense of having a preference ordering satisfying standard assumptions and choosing in line with this ordering)

\footnotetext{
${ }^{1}$ Sobel (2005) is an excellent review of models of interdependent preferences that best explain behaviour in non-market settings, as in laboratory experiments of the 'ultimatum game'.
} 
but rather we question the notion that consumers are narrowly concerned just with their own consumption rather than with their own consumption in relation to those of others in society.

Finally we note that in analysing how individual consumers respond to the consumption of other individual consumers in market settings, it is natural to draw on the tools of game theory for our analysis. Our aim is not to develop new results in game theory itself, but rather to apply standard results in game theory to inter-personal consumer behaviour. We believe our approach yields a number of useful insights in economic analysis, its application to environmental issues and its policy recommendations ${ }^{2}$.

In thinking about how game theory and economics might link to sociologists' accounts of consumption, Warde (1997) noted that the sociology of consumption had for a while been closely linked to sociologists' concern with social class (see, for example, Bourdieu (1984)). In those formulations the individual's habitus shapes her tastes; which means that an individual's lifestyle or consumption pattern is an expression of her class position, involving both attempts to distinguish herself from some groups and to align her tastes with a peer group or class (see also Granovetter (1978)). Warde notes that such analysis leaves little scope for individual choice in consumption, since choices are a by-product of group affiliation, and he contrasts this with accounts such as Bauman (1988) which emphasises the decline of class and the rise of individualism and informalism (the dissolution of rigid and conformist patterns of consumption).

These theoretical accounts extend a long tradition of sociological writings (Simmel (1903), Weber (1980 [1920]), Veblen (1924)) that gave more importance to consumption as a mediator of our sense of identity - who we are and how we see ourselves in relation to others $^{3}$. Summarising this vast body of work, Jenkins (1996) distinguishes between four inter-related dimensions of social identity: I (how I see myself); Me (how I think others see me); Us (who I identify with and who I want to be identified with); and Them (who I want to distinguish myself from). We think of these first two dimensions of identity as providing a more elaborate formulation of economists' concept of individual preferences, which economists simply take to be innate. Jenkins described this division of the four dimensions as 'interior' (to the individual) and 'exterior' (being rooted in collective identities). The second two dimensions of identity are what we shall call socially-embedded preferences - the extent to which an individual's preferences are influenced by the preferences of others.

Later work on the sociology of consumption (especially Bourdieu (1990), Douglas and Isherwood (1979), Warde (1994,1997), Southerton and Warde (2012)) emphasises that how consumption impacts on identity is related not so much to the act of purchasing commodities, which is the focus of most economic analysis of consumption, as to how these commodities are appropriated into practices (e.g. whether a family eats at the same time, or watches television in the same room). So the same commodity can mean something very different across social groups depending on how they are incorporated into practices. The activity-based approach to consumption used by economists and initiated by Lancaster

\footnotetext{
${ }^{2}$ Another illustration of our interest in this topic derives from a conference on Sustainable Consumption: MultiDisciplinary Perspectives, held by the Sustainable Consumption Institute at University of Manchester in 2012. The proceedings (Southerton and Ulph, 2014) include an Introductory chapter which summarises the different disciplinary approaches to consumption.

${ }^{3}$ Simmel's (1903) classic essay argues that a fundamental characteristic of modernity is that individual preference can only be understood - or recognized - through the degree of similarity or difference from the preferences of others.
} 
(1966), in which goods, including commodities and time, are valued not directly for themselves but more as inputs to activities which satisfy higher level goals, bears some relation to the sociological practices approach to consumption. In this paper we shall follow the simpler economic focus on consumption as the purchase of goods (commodities and time $)^{4}$.

We shall be concerned with two different aspects of socially-embedded preferences. The first is competitive consumption, dating back to Veblen (1924), whereby individuals lose esteem if their consumption of some good(s) which signal their status is below the average of the some reference/peer group. Competitive consumption is often held to lead to 'overconsumption', with potentially damaging implications for the use of environmental resources (see, for example, Schor (2010)). The second aspect of socially-embedded preferences is concept of consumption norms in which individuals use consumption of some goods to signal their desire to conform to the consumption norms of some groups with whom they identify. ${ }^{5}$ Unlike competitive consumption, this can lead some individuals to consume less than they might otherwise have done. While this might be thought to be less threatening to overuse of environmental resources, we shall show that consumption norms may have perverse effects for the design of environmental policies.

Socially-embedded preferences arise when an individual's preferences are influenced by what other individuals consume. We shall use the term socially-directed preferences to describe the case where individuals recognise that their own consumption can have negative consequences on others through the environmental damage they impose on others. So they may be willing to voluntarily reduce their consumption of environmentally harmful goods beyond the point which minimises damage to themselves to take account of the damage they cause others. In other words people act altruistically.

This paper will be concerned principally with the broad conceptual analysis of these issues, rather than with applications to any specific good. Nevertheless, it is important to consider what features of commodities or behaviours might make them relevant for our analysis. We believe the key characteristics, particularly for competitive consumption or consumption norms, include: (a) the consumption of these goods needs to be visible to other consumers; (b) they should be goods whose consumption almost all relevant individuals might engage in; (c) they are goods which can provide some form of coordination of individual actions (e.g. common times at which consumption or activities take place); (d) there are implicit social sanctions for deviating from some pattern of consumption - loss of face in the case of competitive consumption or exclusion from a group in the case of consumption norms. For specific issues related to the environment it is obviously important that the consumption of these goods has a significant detrimental effect on the environment.

Now there may be many goods which have the characteristics noted above, and we want to emphasise that our analysis does not seek to explain which commodities emerge as being

\footnotetext{
${ }^{4}$ As Dasgupta (2014) notes, provided the production structure linking inputs of commodities and time to outputs of higher level activities remains constant there is little to be lost by focussing on acquisition of goods. ${ }^{5}$ It is worth noting that consumption norms are not entirely elective as, even in cases where an individual wishes to belong to a group, belonging requires that members of the group recognize and accept that consumption norms are being performed competently (Warde (1994)).
} 
significant for any particular form of social interaction for any particular group ${ }^{6}$. As a related point we will not construct an explicit repeated game formulation of the issues we study, but view our analyses as short cut versions, even reduced forms, of a more explicit analysis. For example, our analysis suggests that, as in most repeated games, there may be multiple equilibria $^{7}$, and it is not possible using game theory itself to determine which of these multiple equilibria will be selected. We look to more detailed anthropological or sociological analyses to address such issues. This relates to a much broader debate in game theory (Mailath and Samuelson (2006))

The structure of the paper is as follows. In the next section we shall set out a general framework and overview of the concepts of socially-embedded and socially-directed preferences and their potential links to environmental damages. In Sections 3 and 4 we will present our analysis of socially-embedded preferences, covering competitive consumption (Section 3) and consumption norms (Section 4). In Section 5, we will present our analysis of socially-directed (altruistic) preferences. Finally, in Section 6 we will consider the implications Sections 3, 4 and 5 for empirical testing of models of consumption with environmental effects, environmental policy design, and directions for future research.

\section{Section 2: General Framework and Overview}

In this section we set out a general framework that underpins all our analysis. We will derive the standard prescriptions of environmental policy, and frame the questions that will be addressed in more detail in subsequent sections.

As noted above, we distinguish between socially-embedded preferences and sociallydirected preferences. With socially-embedded preferences an individual's consumption behaviour is driven by a concern about how her consumption of various commodities relates to the average levels of consumption that prevail in a reference group. This concern is assumed to be a reflection of an individual's concern about her status/esteem. This could in turn reflect both how she assesses herself in relation to others, but also how she thinks others assess her in relation to themselves. ${ }^{8}$ With socially-directed preferences individuals are aware that when there is some public good/externality problem of the kind that arises in environmental economics, individual consumption behaviour can, in aggregate, have consequences both for themselves and for everyone else.

Throughout our analysis we focus on an atomless economy in which aggregate/average consumption is independent of the consumption decisions of any given individual - a fact that individuals are assumed to recognise in making their consumption decisions.

\subsection{Model Background}

Suppose that there are $n$ commodities, and a continuum of individuals of mass $M$. This set of individuals comprises the reference group that influences each individual's consumption decisions.

\footnotetext{
${ }^{6}$ For example, conspicuous consumption might be more pertinent to young people, perhaps because their own preferences have not been fully developed.

${ }^{7}$ This is particularly true in our analysis of consumption norms

${ }^{8}$ In common with much of the economics literature we do not explain which group constitutes the reference group.
} 
Let $c=\left(c_{1}, \ldots, c_{n}\right) \geq 0$ and $y$ denote, respectively, the consumption bundle and income of a single representative individual, while $\bar{c}=\left(\bar{c}_{1}, \ldots, \bar{c}_{n}\right) \geq 0$ and $\bar{y}$ denote, respectively, the average consumption bundle and income.

Let $q=\left(q_{1}, \ldots, q_{n}\right) \geq 0$ denote the vector of producer prices. Assume that all goods are produced in perfectly competitive markets under constant returns to scale. Producer prices therefore equal the (constant) marginal and average costs of production, and so are exogenous. In all that follows we will let $q_{k}, k=1, \ldots, n$ denote both the constant unit cost of producing commodity $k$ and the producer price of commodity $k$.

Because there might be corrective taxes, the prices faced by consumers can be different from producer prices, so let $p=\left(p_{1}, \ldots, p_{n}\right) \geq 0$ be the vector of consumer prices. We assume that, when taxes are imposed, the net tax revenue is remitted to individuals via a lump-sum transfer, $\sigma$.

We allow for the possibility that the aggregate consumption of some commodities might generate environmental damage, $D=d(M \bar{c})$, where the damage function, $d($.$) is assumed$ to be a non-decreasing, convex function of the aggregate consumption of each good.

Before proceeding, we briefly set out as a point of reference the classical theory of environmental economics.

\subsection{Basic Theory of Environmental Economics}

For simplicity, in this sub-section we assume that individuals are identical. In this theory people behave in a purely individualistic fashion. Individual well-being is given by

$$
W=Y-\delta D, \quad \delta \geq 0
$$

where $Y=u(c)>0$ measures what we call well-offness and reflects the enjoyment that individuals derive from the consumption of the various commodities. We take well-offness to be a conventional measure of real income - which it is why it is positive - and, for simplicity, its dependence on prices is suppressed. The utility function $u($.$) is assumed to$ be strictly increasing and concave. The parameter $\delta$ reflects the impact of environmental damage on individual well-being.

In making their consumption decisions individuals take as given: the vector of consumer prices, $p$; their income, inclusive of any transfer, $y+\sigma$; the vector of average consumption, $\bar{c}$; and choose their own consumption bundle, $c$, to maximise well-being,

$$
W=u(c)-\delta d(M \bar{c})
$$

subject to the budget constraint, $p . c \leq y+\sigma$. Since individuals treat average/aggregate consumption - and hence environmental damage - as constant, the resulting consumption levels are just the Marshallian demands characterised by 


$$
\begin{aligned}
& u_{k}(c)=\lambda p_{k}, \quad k=1, \ldots, n \\
& p . c=y+\sigma
\end{aligned}
$$

The social planner sees the connection between individual and average consumption and so chooses $c$ to maximise

$$
W=u(c)-\delta d(M c)
$$

subject to the feasibility constraint $q . c \leq y$. The socially optimal consumption bundle, $\hat{c}$ is characterised by ${ }^{9}$

$$
\begin{aligned}
& u_{k}(\hat{c})=\mu q+\delta M d_{k}(M \hat{c}), \quad k=1, \ldots, n \\
& q . \hat{c}=y
\end{aligned}
$$

This optimum can be supported by a vector of taxes and a lump-sum transfer

$$
t_{k}=p_{k}-q_{k}=\left(\frac{\delta}{\mu}\right) M d_{k}(M \hat{c}), \quad k=1, \ldots, n ; \quad \sigma=t . \hat{c}
$$

which reconcile the solution of (3) with the solution of (5) - i.e. induce self-interested individuals to pick the socially optimal levels of consumption. The tax on good $k$ is just the standard Pigovian specific tax equal to the marginal social cost of a unit increase in average consumption of good $k$, where the marginal social cost is the willingness to pay for a marginal reduction in environmental damage, $\frac{\delta}{\mu}$, multiplied by the marginal increase in damage caused by a unit increase in the average consumption of commodity $k, M d_{k}(M \hat{c})$. For commodities that cause no environmental damage this latter term will be zero.

\subsection{Socially Embedded Preferences}

\subsubsection{Status Goods and Esteem}

In Sections 3 and 4 of the paper dealing with socially embedded preferences we allow for the possibility that some of the commodities might be status goods and that an individual's feeling of esteem/status will depend on some measure of their consumption of good $k$ relative to the average consumption of the reference group. Let $r_{k}=f_{k}\left(c_{k}, \bar{c}_{k}\right), \quad k=1, \ldots, n$ be a variable that captures the relevant status-inducing indicator of a representative individual's consumption of good $k$ relative to that the average consumption of that good. Let $r=\left(r_{1}, \ldots, r_{n}\right)$ be the vector of relative consumption.

\footnotetext{
${ }^{9}$ Here, and throughout the paper we use the notation $u_{k}=\frac{\partial u}{\partial c_{k}} ; \quad d_{k}=\frac{\partial d}{\partial M \bar{c}_{k}}$.
} 
We consider two different theories of the nature of the relationship captured through the functions $f_{k}(.,$.$) .$

\section{- Competitive Consumption}

Here individuals see themselves as competing against their peers to gain esteem. They suffer low esteem if their consumption is lower than the average in the reference group, and high esteem if they are doing at least as well as the average. So the measure of how well they are doing relative to their peers is a strictly increasing function of their own consumption but a decreasing function of average consumption. Formally

$$
\frac{\partial f_{k}}{\partial c_{k}}>0 ; \quad \frac{\partial f_{k}}{\partial \bar{c}_{k}}<0
$$

- Desire for Conformity

Here, individuals gain esteem by conforming to the norm of what everyone else is consuming. They lose esteem if they are too far from the average - above or below. So what matters is the gap between the individual's consumption and that of their peers. The measure of how well an individual is conforming to the norm is therefore strictly increasing in own consumption as long as own consumption is less than the average, whereas it is strictly decreasing in own consumption when this is above the average. Similarly an increase in the average consumption will lower the measure of how well an individual is conforming when own consumption is less than the average, but increase the measure of conformity when own consumption is above the average.

$$
\begin{aligned}
& \frac{\partial f_{k}}{\partial c_{k}}>0, \frac{\partial f_{k}}{\partial \bar{c}_{k}}<0 ; \quad \text { if } \quad c_{k}<\bar{c}_{k} \\
& \frac{\partial f_{k}}{\partial c_{k}}<0, \frac{\partial f_{k}}{\partial \bar{c}_{k}}>0 ; \quad \text { if } \quad c_{k}>\bar{c}_{k}
\end{aligned}
$$

(8a) is similar to (7) and so gives an incentive for the consumer to raise own consumption towards the norm if own consumption is below the norm; but (8b) provides an incentive to narrow the gap between own consumption and the norm by cutting own consumption to bring it closer to the norm. It is in this respect that the desire for conformity differs from competitive consumption ${ }^{10}$.

Notice that if what gives individuals esteem is the sense that they are conforming to some norm of consumption to which others adhere then it is essential that individuals differ in some crucial aspect - income, tastes - that would otherwise have led them to make different consumption choices than their peers.

\subsubsection{Well-being}

\footnotetext{
${ }^{10}$ As Dasgupta (2014) notes while consumption norms may look rather similar to conspicuous consumption, they have quite different analytical and policy implications, as we shall see in Sections 3 and 4.
} 
Individual well-being, $W$, is assumed to depend on three factors:

i. The first is, once again, well-offness $Y=u(c)>0$. Well-being is assumed to be a strictly increasing function of well-offness.

ii. The second factor is individual happiness/status/esteem, which we assume is measured by $H=h(r)$, which is a non-decreasing function of the indicators of relative consumption. Well-being is assumed to be a strictly increasing function of happiness.

iii. The final factor affecting well-being is the environmental damage $D=d(M \bar{c})$ introduced above. Well-being is assumed to be negatively related to $D$.

We assume that the way that these factors can be combined to determine well-being can be written as $^{11}$

$$
W=\theta Y+(1-\theta) H-\delta D, \quad 0<\theta \leq 1, \quad \delta \geq 0 .
$$

The parameter $\delta$ measures the weight given to environmental damage in the well-being function relative to the first two factors ${ }^{12}$. A number of different areas of economic theory are encapsulated within this formulation.

- the parameters $\theta=1, \delta=0$ characterise classical theory - purely individualistic behaviour, no environmental externalities;

- the parameters $\theta=1, \delta>0$ characterise the standard theory of environmental economics - as set out above in section 2.2 - with purely individualistic behaviour but environmental externalities matter;

- the parameters $\theta<1, \delta=0$ characterise socially embedded behavioural theory with no environmental externalities;

- the parameters $\theta<1, \delta>0$ characterise the socially embedded behavioural theory of environmental economics - the focus of Sections 3 and 4 of the paper.

Notice also that the theory is sufficiently general that we can allow for four different kinds of commodities:

- commodities that are neither status goods nor environmentally damaging: $h_{k}=0 ; \quad d_{k}=0^{13}$;

- commodities that are status goods but cause no environmental damage: $h_{k}>0 ; \quad d_{k}=0 ;$

- commodities that are not status goods but do cause environmental damage: $h_{k}=0 ; \quad d_{k}>0 ;$

\footnotetext{
${ }^{11}$ For expositional purposes the precise way in which the various factors are combined to determine wellbeing may vary from section to section. However they are formally equivalent to the specification given in (9)

${ }^{12}$ Throughout the paper we presume that this is sufficiently low that well-being overall is positive.

${ }^{13}$ Here, and throughout the paper we use the notation $h_{k}=\frac{\partial h}{\partial r_{k}}$.
} 
- commodities that are both status goods and environmentally damaging: $h_{k}>0 ; \quad d_{k}>0$.

Having defined the key elements of the theory, we now sketch the structure of the analysis of the socially embedded behavioural theory of environmental economics to which it gives rise.

\subsubsection{Individual behaviour}

As in the standard theory sketched in Section 2.2, a representative individual takes as given: the vector of consumer prices, $p$; their income, inclusive of any transfer, $y+\sigma$; the vector of average consumption, $\bar{c}$, and chooses their own consumption bundle, $c$, to maximise well-being, subject to the budget constraint, $p . c \leq y+\sigma$. The resulting consumption will be a function

$$
c=g(p, y+\sigma, \bar{c})
$$

Notice that, in this optimisation exercise an individual once again treats total emissions and hence environmental damage as constant, and so only takes account of how their own consumption choices affect both well-offness and, to the extent it matters, esteem or happiness. What is different is the potential dependence of individual consumption decisions on the vector of average consumption.

\subsubsection{Nash Equilibrium behaviour}

Because of the dependency of individual decisions on average consumption, then, since all individuals are making the same calculation, we now need to consider a Nash equilibrium in which the average consumption, $\bar{c}$ equals the average of all the consumption decisions that are taken conditional on $\bar{c}$. In the special case where all individuals are identical ${ }^{14}$ this would imply that the equilibrium consumption bundle $c^{e}=\bar{c}^{-e}$ where, from (10),

$$
c^{e}=g\left(p, y+\sigma, c^{e}\right)
$$

It is the need to consider this Nash equilibrium that distinguishes the theory of socially embedded preferences from conventional theory. There are three important implications.

- In the case of competitive consumption behaviour, there can be Red Queen effects everyone is trying to do better than their peers but, in equilibrium, ends up being exactly the same as them.

- There can be multiplier effects at work in determining how equilibrium consumption responds to changes in prices or income. If a change in price or income induces a change in any individual's consumption, it changes everyone's consumption, which changes average consumption which again affects consumption behaviour.

\footnotetext{
${ }^{14}$ As noted above, in the case of conformist behaviour, individuals must necessarily be different. In this case there may be multiple consumption norms, but nevertheless each satisfies the condition that it is the average consumption of those choosing to adhere to that norm.
} 
- However if the effect of average consumption/norms on individual consumption behaviour is sufficiently strong, individual behaviour may not respond to changes in prices or income. This is particularly important in the context of conformist consumption behaviour.

\subsubsection{The Social Optimum}

As in the conventional theory the social planner is assumed to see the connection between individual consumption behaviour and average consumption and will seek to maximise average well-being subject to the feasibility condition $q . \bar{c} \leq \bar{y}$. This will certainly mean that the social planner recognises the environmental implications of the combined effects of individual behaviour. But it also means the social planner will recognise the implications of the combined effects of individual behaviour for consumption norms and individual esteem ${ }^{15}$. The fundamental research question is therefore how the optimal environmental policies change when account is taken of socially embedded preferences. This is the question addressed in Sections 3 and 4 of the paper.

\subsection{Socially Directed Preferences}

In the theory set out in Section 5 of the paper, individuals are not driven by a concern for esteem/status/happiness, so, in relation to the theory set out above, we are dealing with the case where $\theta=1$. What motivates each individual's behaviour is a recognition that, if everyone continues to act in a way that maximises individual well-being, then, absent fully optimal government policy, there will be an excessive amount of environmental damage, from which not only will that individual herself suffer, but so too will others - and that might matter to the individual.

So the first ingredient in a theory of socially directed preferences is the recognition of altruism as a potential driver of behaviour. In the case where individuals are identical this means that the objective that motivates behaviour is $(1+\alpha M) W$ where $\alpha \geq 0$ is the degree of altruism. However if individuals simply maximise this objective then effectively they are just maximising $W$ and nothing will change.

So the second ingredient of the theory of socially directed preferences is that recognition that individuals may make their consumption decisions according to a different calculus, which is that they try to choose the level of consumption that they think is morally right and we take this to be characterised by the Kantian norm of choosing that behaviour that would be optimal if everyone else did the same. So instead of their behaviour conforming to what everyone else does, they think about what would happen if everyone else's behaviour were to conform to their own.

However if individuals believe, correctly, that, in an atomless economy, other people's behaviour will not be affected by their own, then they recognise that behaving according to this alternative calculus incurs a cost in terms of individual well-being, which they may be willing to balance against what they recognise as a purely hypothetical moral gain.

\footnotetext{
${ }^{15}$ This has important implications in the case of conformist consumption where, because individuals are necessarily different. Consequently while individual consumption behaviour might be influenced by a norm, it need not be identical to it, and so the social optimum has to be constructed with some care.
} 


\subsubsection{Individual Behaviour}

As indicated, the theory of individual behaviour now involves individuals choosing their own consumption to balance off the individual cost of behaving "sub-optimally" against the hypothetical moral benefit to them and others of making the "right" choice.

\subsubsection{Social Optimum}

The social planner now not only recognises the connection between individual behaviour when taken together and environmental damage, but also that the moral benefit driving behaviour is purely hypothetical and so chooses consumption to maximise aggregate realised well-being.

As in Sections 3 and 4 the fundamental question we address in Section 5 is how the optimal environmental policy differs from that emerging from the standard theory (as set out Section 2.2) when individuals have socially directed preferences.

In the next two sections we consider two examples of socially-embedded preferences where an individual's preferences are influenced by the consumption of a relevant set of other consumers: competitive consumption and consumption norms.

\section{Section 3: Socially Embedded Preferences - Competitive Consumption}

The central idea in this section is that people care about their status in society - whether they have done well or badly in comparison to some relevant group of peers. There are clearly many factors that might determine status, but it is hard to convey this detail to others, so a short-hand way of signalling status is through the consumption of one or more of a number of status goods - cars, houses, exotic holidays, jewellery etc - that are used as litmus tests of success. For these to work as status goods their consumption has to be clearly observable by others, which is why such consumption is often referred to as conspicuous consumption - a term introduced by Veblen (1924).

We don't try to explain why some goods play this role. Rather we take the existence of such goods as given and critically examine one of the main implications of the existence of such status goods - that they lead to a 'rat race ${ }^{16}$, in which individuals over-consume in order to gain status relative to their peer group and to distinguish themselves from others, with a consequent need to fund this extra consumption by either working harder or saving less (see, for example, Frank (1985), Schor (1998)). This is particularly important given that some of the goods that play this role may also be associated with high levels of pollution, which leads us to examine the implications for environmental policy.

Conspicuous consumption finds expression in any model in which a household's utility is a function not only of its own consumption of goods and services but also of its own consumption relative to the consumption of goods and services by its peer group. A standard economic argument is that because the consumption of other people has a negative effect on an individual's utility, this is a form of externality which should be corrected by a tax on goods whose consumption is deemed conspicuous ${ }^{17}$. This would be in addition to any

\footnotetext{
${ }^{16}$ Sometimes referred to as "Keeping up with the Joneses"

17 The Veblen effect has also been invoked to help explain the Easterlin Paradox (Easterlin (1974), (2001)) whereby average life satisfaction (as measured by surveys of happiness) in advanced economies has stayed
} 
Pigovian tax imposed to reduce the damage to the environment. In sub-section 3.1 we use the general model set out in section 2 to analyse the policy implications of these two distortions.

In sub-section 3.2 we will consider a special case of this general model, building on Arrow and Dasgupta (2009), who developed an inter-temporal ${ }^{18}$ model of consumer behaviour in which, depending on what is assumed about how many goods (including leisure) are subject to a conspicuous consumption effect and the precise form of individuals' utility functions, the existence of a conspicuous consumption effect may lead to no market distortion. However their basic argument does not depend on their inter-temporal structure, and the atemporal model we will employ captures their key insight, though we also show that we can extend their result to include environmental externalities.

\subsection{A Model of Conspicuous Consumption with Environmental Damages}

Following the general model set out in section 2, we consider a timeless economy with a continuum of identical individuals of mass $M=1^{19}$, who are distributed uniformly in the unit interval. We assume that individuals are identical and that there are $n$ goods, indexed $k=1, \ldots, n$. Let $c=\left(c_{1}, \ldots, c_{n}\right)>0$ denote a single individual's consumption bundle, and $\bar{c}=\left(\bar{c}_{1}, \ldots, \bar{c}_{n}\right)>0$ the vector of average consumption levels. A more general formulation would postulate the existence of a set of, possibly overlapping, peer groups - one peer group for each individual and one set of peer groups across individuals for each consumption good. We simplify by imagining that each individual's peer group is the entire population. Let

$r_{k}=\frac{c_{k}}{\bar{c}_{k}}, \quad k=1, \ldots, n$ be the individual's consumption of commodity $k$ relative to that of its peers, and let $r=\left(r_{1}, \ldots, r_{n}\right)$ be the vector of relative consumption. We denote by $u(c)$ the conventional utility function of the representative individual and by $h(r)$ the happiness of the individual where these are standard strictly increasing concave functions.

Each good is produced in perfectly competitive markets with constant returns to scale and we denote by $q_{k}>0, k=1, \ldots, n$ the set of producer prices, which are exogenous. Because there might be corrective taxes we denote the set of consumer prices by $p_{k}, k=1, \ldots, n$. The individual's exogenously determined income ${ }^{20}$ is denoted $y$, and because the government may be setting corrective taxes we assume that such tax revenues are redistributed in a lump-sum fashion to each individual, where the lump-sum income is $\sigma$.

constant over the past few decades, despite rising levels of per capita income. This is consistent with the 'Red Queen effect' whereby everybody increases consumption to try to do better than their peers, but in the end this is self-defeating because everyone's consumption increases.

${ }^{18}$ Cowan, Cowan and Swann (1997) present a simple model of the dynamics of how consumption might evolve as people seek to make their consumption more like those of an aspiration group and differentiate it from those in a distinctive group. But their model does not allow for welfare analysis.

${ }^{19}$ For the purposes of this section there is nothing to be gained by allowing $M$ to be a variable which could take values greater than 1 .

${ }^{20}$ We could think of one of the goods being leisure and so embed a model of labour supply but for the purposes of this section we do not explicitly identify leisure. 
Every household experiences environmental damage, $D$, which is assumed to be a nondecreasing and convex function $D=d(\bar{c})$ of the vector of aggregate / average consumption of each good.

So individual well-being is given by:

$$
W(c ; \bar{c})=\theta u(c)+(1-\theta) h(r)-\delta d(\bar{c})
$$

where $0<\theta \leq 1 ; \delta \geq 0$. As noted in section 2 , if $0<\theta<1, \delta>0$ we have the general model where both the conspicuous consumption and environmental externalities are present; if $\theta=1, \delta>0$ we have the special case where only the environmental externality is present; if $0<\theta<1, \delta=0$ we have the special case where only the conspicuous consumption externality is present; finally if $\theta=1, \delta=0$ neither is present. We set out the model for the general case.

\subsubsection{The Market Economy}

In an atomless market economy the representative individual takes as given the average consumption of each good $\bar{c}$, and hence environmental damage, caused by each good. So the individual chooses $c_{k}, \quad k=1, \ldots, n$ to maximize (12) subject to the budget constraint:

$$
\sum_{k=1}^{k=n} p_{k} c_{k}=y+\sigma
$$

where, as explained in Section 2, $\sigma$ is a lump-sum transfer that is funded by any corrective taxes that may be imposed on various commodities

The first order conditions of the maximization problem are:

$$
\theta u_{k}(c)+(1-\theta) \frac{1}{\bar{c}_{k}} h_{k}(r)=\phi p_{k}
$$

where $\phi>0$ is the Lagrange multiplier associated with the budget constraint in (13).

Expressions (13) and (14) characterise the consumption choices of a typical individual, taking as given the average consumption of each good, $\bar{c}_{k}$.

In general this determines an individual's consumption of each good as a function of prices, income and the vector of average consumption levels. The precise nature of this relationship depends on the functional form assumed for $h($.). In some formulations average consumption will not appear in (14) so the externality works solely through increasing the weight that individuals attach to the status goods, but the average level of consumption of these goods exerts no influence on individual consumption decisions ${ }^{21}$. In what follows we assume that the solution to (13) and (14) has the property that an individual's consumption of a status good is an increasing function of the average consumption of that good.

\footnotetext{
${ }^{21}$ See for example Boskin and Sheshinski (1978) where individual well-being depends on average consumption, but average consumption has no effect on individual labour supply.
} 
To complete the analysis we have to determine this average level of consumption. Since each individual's consumption depends on the consumption of other individuals, and since, in making their consumption choices, each individual takes as given the consumption of others, in order to move from individual household consumption to the simultaneous determination of the equilibrium consumption of all households, the relevant equilibrium concept is that of a non-cooperative Nash equilibrium. Because, by assumption, individuals are identical, in the non-cooperative Nash equilibrium the consumption of each good will be the same across all individuals. In particular this implies that $c_{k}=\bar{c}_{k} \Rightarrow r_{k}=1 \quad \forall k=1, \ldots, n$.

So, given our assumptions, there is a unique market equilibrium, denoted $c_{k}^{e}, \quad k=1, \ldots, n$ characterised by: $:^{22}$

$$
\theta u_{k}\left(c^{e}\right)+(1-\theta) \frac{1}{c_{k}^{e}} h_{k}(1)=\phi p_{k}
$$

and the budget constraint

$$
\sum_{k=1}^{n} p_{k} c_{k}^{e}=y+\sigma
$$

An important difference between individual behaviour as characterised by (13)-(14) and market behaviour as characterised by (15)-(16) is that the latter will be subject to multiplier effects. So a change in some exogenous factor - such as price - that brings about a change in each individual's consumption of some status good $k$, say, will cause the average consumption to change and, given the assumption made above, this will cause a further change in each individual's consumption of good $k$, causing the average to change againand so on.

\subsubsection{The Socially Optimizing Economy}

Now consider the socially optimal allocation. Because individuals are identical and utility is strictly concave, the social planner will want everyone to consume the same amount of each good. That is the social planner will enforce the condition that for all $k$ and all individuals $c_{k}=\bar{c}_{k} \Rightarrow r_{k} \equiv 1, k=1, \ldots, n$. The social planner's problem is therefore to choose the level of consumption of each good (the same for every individual) in order to maximise:

$$
\theta u(c)+(1-\theta) h(1)-\delta d(c)
$$

subject to the feasibility constraint

$$
\sum_{k=1}^{n} q_{k} c_{k}=y
$$

\footnotetext{
${ }^{22}$ By $h_{k}(1)$ we mean the partial derivative of the function $h$ w.r.t. its $k$-th argument, evaluated at the vector $r$ for which every element is 1 .
} 
The socially optimal allocation, denoted $\hat{c}=\left(\hat{c}_{1}, \hat{c}_{2}, \ldots, \hat{c}_{n}\right)$ is the unique solution of equations

$$
\theta u_{k}(\hat{c})-\delta d_{k}(\hat{c})=\varphi q_{k} \quad k=1,2, \ldots, n
$$

and the feasibility constraint

$$
\sum_{k=1}^{n} q_{k} \hat{c}_{k}=y
$$

where $\varphi(>0)$ is the Lagrange multiplier associated with the feasibility constraint.

From (15) define $\lambda_{k}, \quad k=1, \ldots, n$ by:

$$
\frac{1}{c_{k}^{e}} h_{k}(1)=\lambda_{k} u_{k}\left(c^{e}\right), \quad k=1, \ldots, n
$$

and from (19) define $\mu_{k}, \quad k=1, \ldots, n$ by:

$$
d_{k}(\hat{c})=\mu_{k} u_{k}(\hat{c}), \quad k=1, \ldots, n
$$

\subsubsection{Policy Analysis}

We want to determine the policy which will ensure that the market equilibrium vector of consumption $c^{e}$ coincides with the socially optimal vector of consumption $\hat{c}$. We suppose there is one good, good $n$, which is subject to neither the Veblen effect $\left(h_{n} \equiv 0\right)$ nor the environmental externality, $\left(d_{n} \equiv 0\right)$. Without loss of generality we set $q_{n}=1$, and since there can always be one untaxed good, we also set $p_{n}=1$, so good $n$ acts as a numeraire. From (15) and (19) $u_{n}\left(c^{e}\right)=u_{n}(\hat{c}) \Rightarrow \varphi=\phi$.

Then, from (19), we have for any good $k=1, . ., n-1$

$$
\theta u_{k}(\hat{c})=\varphi q_{k}+\delta d_{k}(\hat{c})
$$

while from (15) and (21)

$$
\theta u_{k}\left(c^{e}\right)\left[1+\frac{(1-\theta) \lambda_{k}}{\theta}\right]=\varphi p_{k}
$$

Define $\xi \equiv 1 / \varphi$ as the marginal willingness to pay for a one unit increase in utility.

Then from (23) and (24) we have that if $c^{e}=\hat{c}$ :

$$
p_{k}=\left[1+\frac{(1-\theta) \lambda_{k}}{\theta}\right]\left[q_{k}+\delta \xi d_{k}\right]
$$


Proposition 1: In an economy subject to both conspicuous consumption and environmental externalities the optimal policy ${ }^{23}$ involves imposing on each good $k=1, \ldots, n-1$ a specific Pigovian tax equal to the marginal social damage cost of good $k\left(\tau_{k} \equiv \delta \xi d_{k}\right)$ and an ad valorem conspicuous consumption tax $t_{k}=\frac{(1-\theta) \lambda_{k}}{\theta}$ so the market price of good $k$ is $p_{k}=\left(1+t_{k}\right)\left(q_{k}+\tau_{k}\right)$.

Its straightforward to see that if there are no conspicuous consumption effects $(\theta=1)$ then the optimal policy just involves specific Pigovian taxes while if there are no environmental damage effects $(\delta=0)$ the optimal policy just involves conspicuous consumption ad valorem taxes.

The following two corollaries illuminate some key features of this result.

Notice first that, if we multiply both sides of (21) by $c_{k}$ then $\lambda_{k}=\frac{r_{k} h_{k}}{c_{k} u_{k}}$ which we can interpret as the weight of commodity $k$ in generating status relative to its weight in contributing to the direct pleasure of consumption. So we have

Corollary 1 The ad valorem tax that is applied to commodity $k$ to correct for potential Veblen effects depends on:

(i) The relative weight in wellbeing of status to the direct pleasure/utility from consumption - i.e. $\frac{1-\theta}{\theta}$;

(ii) the weight of commodity $k$ in generating status relative to its weight in contributing to the direct pleasure of consumption - i.e. $\lambda_{k}=\frac{r_{k} h_{k}}{c_{k} u_{k}}$.

The implication of this second point is that the fact that a commodity contributes a great deal to status is not necessarily a reason for having a high corrective tax. The tax might be quite low if that commodity contributes even more to the pleasure of consumption.

Corollary 2 If commodity $k$ is both a status good and causes environmental damage, the ad valorem tax to correct the distortion generated to the Veblen effect is applied to the price that includes the specific tax to correct for the environmental externality.

So the taxes required to correct these two externalities are not additive but multiplicative.

\subsection{Two Special Cases}

Proposition 1 gives the general policy prescription for an economy with both conspicuous consumption and environmental taxes. It rests on the assumption that there is at least one commodity that is neither a status good nor a source of environmental damage. We now consider two very special cases of the conspicuous consumption model where this

\footnotetext{
${ }^{23}$ The optimal policy will also involve a lump-sum transfer to re-distribute the tax revenue raised from the Pigovian and Veblen taxes back to households.
} 
assumption is dropped. The analysis in this sub-section extends the result of Arrow and Dasgupta (2009) to include environmental externalities.

\subsubsection{First Special Case}

Suppose that all goods are subject to both conspicuous consumption and environmental externalities, and from (21) and (22) suppose that:

$$
\forall k=1, \ldots, n \quad \lambda_{k}=\lambda, \mu_{k}=\mu
$$

Corollary 3: Suppose condition (26) holds. Then the unregulated market equilibrium coincides with the socially optimal allocation and there is no need for policy intervention.

Proof: With no regulation we have $p_{k}=q_{k} \quad \forall k$; from (21) and (22) we have:

$\forall k=1, \ldots, n \quad(1+\lambda) u_{k}\left(c^{e}\right)=\phi q_{k} ; \quad(1-\mu) u_{k}(\hat{c})=\varphi q_{k} ;$ recalling that $q_{n}=1$ we have:

So:

$$
\frac{u_{k}\left(c^{e}\right)}{u_{n}\left(c^{e}\right)}=q_{k} ; \quad k=1, . ., n-1 ; \quad \sum_{k=1}^{k=n} q_{k} c_{k}^{e}=y
$$

$$
\frac{u_{k}(\hat{c})}{u_{n}(\hat{c})}=q_{k} ; \quad k=1, \ldots, n-1 ; \quad \sum_{k=1}^{k=n} q_{k} \hat{c}_{k}=y
$$

We assume these equations have a unique solution, so $c_{k}^{e}=\hat{c}_{k} \quad \forall k$.

QED.

So we get the rather striking, though very special, result that despite there being two sources of distortion to the consumption of each good, with both the Veblen effect and the environmental externality potentially causing overconsumption of each good ${ }^{24}$, there is a set of conditions under which the unregulated market equilibrium and the social optimum coincide. So while one expects there to be a need for both a Pigovian tax on each good to reflect marginal damage costs and a tax on consumption of each good to correct the overconsumption, there are parameter values where no policy intervention may be needed.

With $0<\theta<1, \quad \delta>0$ this result generalises the atemporal version of the result of Arrow and Dasgupta (2009) to allow for both conspicuous consumption and environmental externalities. If $0<\theta<1, \delta=0$ we get just the atemporal version of the result by Arrow and Dasgupta (2009), while if $\theta=1, \quad \delta>0$ we get a version of the Arrow and Dasgupta result when there are only environmental externalities.

\footnotetext{
${ }^{24}$ That competitive consumption may well also be resource intensive (conspicuous consumption in automobiles and air travel) should not surprise. The gap between the market price and social worth of environmental resources has meant that technological innovations are biased against nature. Entrepreneurs, understandably, seek innovations that economize on expensive factors of production, not those that are cheap. It should be no surprise, then, that modern technology is rapacious in its use of nature's services.
} 


\subsubsection{Second Special Case}

Now suppose that for $k=1, \ldots, \tilde{n} \quad \theta<1, \delta=0 ; \quad k=\tilde{n}+1, \ldots, n \quad \theta=1, \delta>0$ so that for the first $\tilde{n}$ goods the Veblen effect is the only externality that applies, while for the remaining goods it is only the environmental externality that applies. In (21) and (22) suppose that:

$$
k=1, \ldots, \tilde{n} \quad \lambda_{k}=\lambda>0, \mu_{k}=0 ; \quad k=\tilde{n}+1, \ldots, n \quad \lambda_{k}=0, \mu_{k}=\mu>0
$$

Then we have

Corollary 4: Suppose condition (27) holds. Then if $\mu=\frac{\lambda}{1+\lambda}$ the unregulated market equilibrium coincides with the socially optimal allocation and there is no need for policy intervention.

Proof: With no regulation we have $p_{k}=q_{k} \quad \forall k$; from (27) we have:

$$
\begin{aligned}
& \forall k=1, \ldots, \tilde{n} \quad u_{k}\left(c^{e}\right)=\frac{\phi}{(1+\lambda)} q_{k} ; \quad u_{k}(\hat{c})=\varphi q_{k} ; \\
& \forall k=\tilde{n}+1, \ldots, n \quad u_{k}\left(c^{e}\right)=\phi q_{k} ; \quad u_{k}(\hat{c})=\varphi(1-\mu) q_{k}
\end{aligned}
$$

recalling that $q_{n}=1$ we have:

$$
\begin{aligned}
& \frac{u_{k}\left(c^{e}\right)}{u_{n}\left(c^{e}\right)}=\frac{q_{k}}{1+\lambda} ; \quad k=1, . ., \tilde{n} ; \quad \frac{u_{k}\left(c^{e}\right)}{u_{n}\left(c^{e}\right)}=q_{k} ; \quad k=\tilde{n}+1, \ldots, n ; \quad \sum_{k=1}^{k=n} q_{k} c_{k}^{e}=y \\
& \frac{u_{k}(\hat{c})}{u_{n}(\hat{c})}=(1-\mu) q_{k}=\frac{q_{k}}{1+\lambda} ; \quad k=1, \ldots, \tilde{n} ; \quad \frac{u_{k}(\hat{c})}{u_{n}(\hat{c})}=q_{k} ; \quad k=\tilde{n}+1, \ldots, n ; \quad \sum_{k=1}^{k=n} q_{k} \hat{c}_{k}=y
\end{aligned}
$$

We assume these equations have a unique solution, so $c_{k}^{e}=\hat{c}_{k} \quad \forall k$. QED.

So again if the special conditions apply, there may be no need for government policy to correct the two distortions. The intuition is straightforward. If the second group of commodities cause environmental damage then, in the optimum, one will want to reduce their consumption and so have relatively higher levels of consumption of the first group of commodities. But if these are subject to Veblen effects, then this might be happening anyway even without government intervention.

Of course, because it may be very difficult for regulators to calculate whether the conditions for Corollary 3 or Corollary 4 apply, a more appropriate way to frame this result might be for regulators to impose appropriate environmental and conspicuous consumption taxes to all goods to which these distortions apply, and if the conditions for either Corollary 3 or Corollary 4 apply then the regulated market equilibrium will coincide with the unregulated market equilibrium.

The basic insight behind both these cases is as follows. First, with a fixed budget/resource constraint, it is impossible to overconsume all commodities. Second, and more importantly, if the factors generating this propensity for over-consumption apply with equal force to all 
commodities then the resulting pattern of consumption will be that which would emerge if there were no distortions, so there is no role for policy to reduce distortions by changing the mix of goods consumed. We emphasise again the very special context within which this result is derived, namely that the environmental externality is generated only by consumers' choices of the goods they wish to consume. So there are no other potentially endogenous factors influencing the way in which these goods are produced or consumed - e.g. the amount of energy households use in laundry or the amount of recycling they conduct which would also affect the level of environmental damage.

\subsubsection{A Particular Example}

As noted by Arrow and Dasgupta (2009), the interesting question is whether there are utility functions and damage cost functions for which there are parameter values satisfying (21) and $(22)^{25}$. The following example shows that Corollaries 3 and 4 can hold when both the utility function, happiness function and damage cost function take a widely used functional form, namely Cobb-Douglas. So we suppose $n=2$ and that the utility function, happiness function and damage cost function take the forms:

$$
u\left(c_{1}, c_{2}\right)=B c_{1}^{\beta} c_{2}^{(1-\beta)} ; h\left(r_{1}, r_{2}\right)=G r_{1}^{\gamma} r_{2}^{(1-\gamma)} ; d\left(\bar{c}_{1}, \bar{c}_{2}\right)=F\left(\bar{c}_{1}^{\omega} \bar{c}_{2}^{(1-\omega)}\right)^{\eta}
$$

where $^{26 .}: \quad 0 \leq \beta, \gamma, \omega \leq 1 ; \quad \eta \geq \operatorname{MAX}\left[\frac{1}{\omega}, \frac{1}{1-\omega}\right]$

Then it is straightforward to show that the unregulated market equilibrium and social optimum levels of consumption of good 1 are characterised by $^{27}$ :

$$
\frac{q_{1} c_{1}^{e}}{y}=\frac{\beta \theta u+\gamma(1-\theta) H}{\theta u+(1-\theta) H} ; \quad \frac{q_{1} \hat{c}_{1}}{y}=\frac{\beta \theta u-\eta \omega \delta D}{\theta u-\eta \delta D}
$$

To illustrate Corollary 3 , note that if $\beta=\gamma=\omega$ then $\frac{q_{1} c_{1}^{e}}{y}=\frac{q_{1} \hat{c}_{1}}{y}=\beta$, so $c_{1}^{e}=\hat{c}_{1}$, while the resource constraint, $q_{1} c_{1}+c_{2}=y$, also ensures that $c_{2}^{e}=\hat{c}_{2}$. Thus we have:

Example 1: If the utility function and damage cost function have the Cobb-Douglas form in (28) then if $\beta=\gamma=\omega$ the unregulated market equilibrium and the social optimum coincide.

So if, for each good, its weight in direct utility is the same as its weight in relative consumption and its weight in environmental damage costs, then the market equilibrium and the social optimum coincide and there is no need for policy intervention. As with Corollary 3 , this example also applies if there is only a conspicuous consumption externality - i.e. $\delta=0$ - or only an environmental externality - i.e. $\theta=1$.

\footnotetext{
${ }^{25}$ Arrow and Dasgupta consider a range of functional forms and parameter values for which Corollary 3 obtains. The Cobb-Douglas functional form we consider is just one such special case.

${ }^{26}$ The restriction on the parameter $\eta$ is required to ensure that the damage function is convex

${ }^{27}$ Notice that in both the equilibrium and optimum $r_{1}=r_{2}=1 \Rightarrow H=G$
} 
To illustrate Corollary 4, assume now that for good 1 only the conspicuous consumption effect applies - i.e. $\omega=0$ - while for good 2 only the environmental externality applies - i.e. $\gamma=1$. Define: $\Omega \equiv \frac{(1-\theta) h(1)}{\theta u\left(c^{e}\right)}=\frac{(1-\theta) G}{\theta u\left(c^{e}\right)} ; \quad \Psi \equiv \frac{\delta d(\hat{c})}{\theta u(\hat{c})}$ and notice that, in order for the consumption levels in (29) to be positive, the parameters $\delta, B, F, G$ will have to be such that $\Omega>0 ; \quad 0<\Psi<1$.

Then it follows immediately from (29) that:

$$
\frac{q_{1} c_{1}^{e}}{y}=\frac{\beta+\Omega}{1+\Omega} ; \quad \frac{q_{1} \hat{c}_{1}}{y}=\frac{\beta}{1-\Psi} \Rightarrow c=\hat{c}_{1} \Leftrightarrow \beta=\frac{\Omega(1-\Psi)}{\Omega+\Psi} .
$$

Example 2: If (i) the underlying functions are Cobb-Douglas as in (28); (ii) $\omega=0$ and $\eta=1$; (iii) the parameter $\beta$ and the other parameters are such that the condition in (30) holds, then the unregulated market equilibrium and the social optimum coincide.

Again we emphasise that this is a very special case, and that in general the best policy is to impose Pigovian taxes and taxes to correct overconsumption on appropriate commodities, and there will be particular sets of utility functions and damage cost functions with very particular parameter values, where the regulated market equilibrium turns out to be identical to the unregulated market equilibrium.

\section{Section 4: Socially Embedded Preferences - Consumption Norms}

In the previous section consumption decisions of individuals were influenced by those of others in a competitive manner as individuals sought to match their consumption to that of an aspirational group (and differentiate it from that of a distinction group). Such forms of externality can sustain overconsumption and a market distortion that needs to be corrected by a policy such as a tax on goods prone to conspicuous consumption, which is additional to any Pigouvian tax needed to correct an environmental externality caused by consumption. In this section we consider a different route by which individuals' consumption decisions may be influenced by those of others, namely through a desire to be seen to belong to a group of similar-minded individuals, thereby establishing consumption norms ${ }^{28}$. A key difference between this section and the last section is that this desire to conform to a consumption norm can lead some individuals to reduce their consumption of a good relative to what they would have consumed in the standard economists' model where consumers take no account of the consumption of others.

There are a number of potential direct benefits that consumers might derive from adhering a consumption norm (see for example Hargreaves-Heap (2013), Hargreaves-Heap and Zizzo (2009)). These include: (a) observing members of a norm group consuming a product an individual has not experienced can give implicit information about the quality of that product; (b) in a related manner, giving people information about what similar people achieve in

\footnotetext{
${ }^{28}$ The most influential sociological theories of consumption - especially Bourdieu's (1984) account of taste and distinction and Bauman's (1990) account of neo-tribal lifestyles - both present social norms and belonging as the fundamental mechanisms underpinning its contemporary social patterning (see Southerton (2002) for a full discussion). In our use of the term consumption norms should be interpreted as a subset of the much broader category of social norms which can affect behaviour.
} 
saving energy, or retirement savings can significantly increase levels of savings (Allcott $(2011))^{29}$; (c) by developing trust between members of a norm group it can reduce transactions $\operatorname{costs}^{30}$; (d) for a number of consumption activities, such as reading a book or attending a concert, the benefits are not just the private experience but the subsequent opportunity to share thoughts about such experiences (the 'water cooler' effect) and this requires individuals to have overlapping sets of cultural interests; (e) for activities like provision of public goods, voting, or charitable giving evidence suggests that individuals are more willing to contribute if they know members of their norm group have contributed (Frey and Meier (2004), Tan and Bolle (2007), Gerber and Rogers (2009), Bucholz, Falkinger and Rubbelke (2012)).

Over and above such direct benefits, however, Akerlof and Kranton (2000) have argued that an ability to identify with a group of people is a key part of self-identity and yields an important psychological benefit of belonging to a group, what Adam Smith referred to as the 'special pleasure of mutual sympathy'31. In the model of Ulph and Ulph (2014), which we summarise in this section, it is this pure psychological benefit of belonging to a group that we have in mind.

Much of the literature on consumption norms does not provide a formal model of how consumption norms might emerge. The paper that is closest to the model reported here is the study by Bernheim (1994) of conformity. In his model people differ in terms of their types (measured by a single index distributed over some interval). Society has a pre-specified notion of an ideal type and people suffer a loss of self-esteem the further their type is from the ideal. Individual's well-being depends on the utility they get from their actions, and the esteem in which they are held by others. If an individual's type was public information, all an individual could do is to act to maximise utility. But an individual's type is private information, and has to be inferred from one's actions, so individuals have an incentive to bias their actions towards that which an ideal person would perform; this leads some individuals to do more than they would do to maximise utility and others to do less. There are two possible equilibria: a fully-revealing equilibrium and a pooling equilibrium in which a group of individuals whose types are closer to the ideal type carry out the same level of action - so the equilibrium specifies a common action norm and the group of people who adhere to this common norm.

In Ulph and Ulph (2014) we focus directly on consumption behaviour and consumption norms, and we examine how behaviour influenced by such norms relates to traditional analysis of consumer demand captured by Marshallian demand curves. Like Bernheim we want to explain endogenously how consumption norms change individual consumer behaviour, which consumption norms can emerge as equilibrium norms, and how many

\footnotetext{
${ }^{29}{ }^{29}$ See Bennett et al (2009) for a comprehensive analysis of the clustering of consumption activities based on overlapping cultural interests in the UK.

${ }^{30}$ This is linked to notions of social capital. It is important to distinguish between group membership developing greater trust between insiders - a positive social benefit - and developing a greater distrust of outsiders - a reduction in social benefit (see Putnam (2000) and Dasgupta (2000) for a recognition that social capital may have negative as well as positive effects). Hargreaves-Heap and Zizzo (2009) construct a measure to test this distinction, and in their experiments they find it is the negative effect which predominates.

${ }^{31}$ Hargreaves-Heap and Zizzo (2009) also develop a test to measure this psychological benefit of belonging to a group; they find that it balances out the negative effect of group membership noted in the previous footnote.
} 
norms there might be. All behaviour is individual - there is no process for communication or coordination.

Unlike Bernheim all information is public. In particular, to rule out other channels of interactions, we assume consumers are perfectly informed about the quality of the commodities being consumed and consumption is a private good. The crucial difference is that there is no concept of an ideal type of consumption, and the motivation to belong to a group is the pure psychological benefit discussed above. We also develop the welfare analysis of the model and use it to draw policy conclusions, including environmental policy.

In this section we set out a special case of the more general model in Ulph and Ulph (2014).

\subsection{A Model of Consumption Norms}

In relation to the general model we set out in section 2, for simplicity we assume ${ }^{32}$ that there is a unit mass of consumers - i.,e. $M=1$ - and that there are just 2 goods: good 1 which is both the consumption norm good and generates environmental externalities and good 2 which is expenditure on all other consumption and is neither a norm good nor does it generate environmental externalities ${ }^{33}$. Good 2 is the numeraire good and its producer and consumer price is 1 .

We drop commodity subscripts, so, for good 1, its consumption is denoted by $c$, its consumer price by $p$, and its producer price by $q$. We assume that the emissions produced by the production/consumption of good 1 is proportional to aggregate output and that the damage function is linear in emissions. Consequently the damage costs experienced by every consumer, are $D=\delta \bar{c}$, as before, $\bar{c}$ is the average level of consumption of good 1 , and $\delta>0$ is the weight consumers place on environmental damage. We assume that the market for good 1 is perfectly competitive so its producer price $q$ equals the constant unit cost of production. The government imposes a Pigovian tax $t=\delta$ on good 1, so, ignoring for just now any policy to deal with consumption norms, $p=q+t=q+\delta$. As set out in section 2 , we assume that the tax revenue raised by the Pigovian tax is redistributed as a lump sum subsidy, $\sigma$, and that the individual has income from other sources denoted $y$. To save notation we denote the consumer's total income by $\hat{y}=y+\sigma$.

Individuals can choose whether or not to adhere to a norm. If an individual chooses not to adhere to a norm, a typical consumer has utility function:

$$
U(c, \hat{y}-p c)=A c-0.5 c^{2}+\hat{y}-p c-D
$$

with corresponding Marshallian demand for good $1: c^{m}(p, A)=c^{m}(p, A ; \hat{y})=A-p$. In this model income $\hat{y}$ plays no role in behaviour so there is no loss of generality in assuming it is the same for all consumers.

\footnotetext{
${ }^{32}$ As we did in Section 3.

${ }^{33}$ We need to interpret the concept of a good acting as a consumption norm broadly, to encompass not just the characteristics of the good, but also the practices in which the good is deployed; so hosting a dinner party involves more than just the food and wine served but how it is served, the conversation that takes place etc.
} 
If instead the consumer has chosen to adhere to some consumption norm $c *$ then the utility of the typical consumer is now:

$$
U(c, \hat{y}-p c ; \gamma, \Gamma)=A c-0.5 c^{2}+\hat{y}-p c-\gamma\left|c-c^{*}\right|+\Gamma-D
$$

where $\gamma$ measures what we call the individual's strength of adherence to the norm ${ }^{34}$, or the utility cost per unit of consumption that differs from the norm, and $\Gamma$ measures the strength of the desire for conformity - the pure psychological benefit the individual experiences from adhering to a norm, as discussed above. We emphasise that the norm $c *$ is not chosen by any individual or group of individuals - it has emerged from past custom and practice.

For the special case presented in this paper we assume and there are just two types of consumers; a fraction $\pi$ have low demand for good 1, so $A$ takes the value $A_{L}>p>0$ while the remaining fraction $(1-\pi)$ of consumers have high demand where $A$ takes the value $A_{H}>A_{L}$; the average value of $A$ is $\bar{A}=\pi A_{L}+(1-\pi) A_{H}$.

There is a four-stage game. In stage 1 the government sets policy. In stage 2 the consumer decides whether to adhere to the prevailing norm or go it alone and choose the Marshallian demand. There are three elements to this choice. First if, by adherence to a norm, the choice of consumption differs from the Marshallian demand level, then this will reduce the consumer's well-being, since the Marshallian demand maximises well-being absent any consideration of norms. Second, although the consumer adheres to a norm, and the chosen level of consumption is influenced by the norm, as we will see the chosen level of consumption may still differ from the norm. For, given the first factor mentioned above, there may be only so far that consumers are willing to go away from their Marshallian demand in order to adhere to the norm. But, third it assumed that by adhering to a norm the consumer derives a direct benefit to well-being represented by $\Gamma$ - what we call the strength of desire for conformity. Since the first two factors reduce well-being, if this third factor were not present the consumer would never adhere to a norm. It is the balance of these three elements which will determine whether the consumer chooses to adhere to a norm or to simply choose its Marshallian level of demand. In stage 3 we determine which norms could serve as equilibrium norms. Finally in stage 4 the consumer chooses what to consume, conditional on whether or not adherence to a norm has been chosen in stage 2 . We work

\footnotetext{
${ }^{34}$ We note three points about the way we formulate the concept of the utility loss from not adhering strictly to the norm. First, since good 1 is both a norm good and emits environmental damage a referee asked why a consumer whose consumption was below the norm would want to increase consumption and hence emissions. We assume that the issue of a consumption norm is distinct from the issue of environmental damage caused by good 1 , and we make the conventional assumption (see section 2 ) that the consumer believes the impact of her consumption on environmental damages is negligible. Second the referee asked why the distance between actual consumption and the norm should matter rather than wanting to hit the norm exactly. We assume that the norm does not a invoke 'taboo trade-off', i.e. it has such a powerful moral value that individuals would feel moral outrage if faced with such a trade-off (see Tetlock (2003) and Croson and Treich (2014)). Our formulation is consistent with Bernheim (1994). Third, note if we had expressed the cost of deviating from the norm in the more standard form as $0.5 \gamma\left(c-c^{*}\right)^{2}$ then the first-order condition for optimal consumption would be: $A-c-p-\gamma\left(c-c^{*}\right)=0$ so if $c=c^{*}$ then $c^{*}=c^{m}(p, A)$ so consumers will only consume the norm level of consumption when the norm equals their Marshallian demand, and so is what they would have chosen to consume had they not adhered to a norm.
} 
backwards; in stages 3 and 4 the consumer treats $\Gamma$ and $D$ as constants, so to reduce notation we shall omit these elements in discussing these two stages.

For the reasons set out above, when consumers choose to adhere to a norm it will still be important to keep track of their Marshallian demands and how these differ from the consumption decisions that they actually make.

\section{$\underline{4.1 .1}$ Stage 4}

The solution to maximising (31) can be expressed as follows: there is a norm-consistent interval of consumption $[\underline{\underline{c}}(p, A, \gamma), \bar{c}(p, A, \gamma)]$ where:

$$
\begin{aligned}
& \stackrel{c}{=}(p, A, \gamma)=c^{m}(p, A)-\gamma \\
& =\bar{c}(p, A, \gamma)=c^{m}(p, A)+\gamma
\end{aligned}
$$

such that the consumption choice of the individual is

$$
\begin{aligned}
& c\left(p, A, \gamma, c^{*}\right)=c^{*} \Leftrightarrow \underline{\underline{c}}(p, A, \gamma) \leq c^{*} \leq \overline{\bar{c}}(p, A, \gamma) \\
& c\left(p, A, \gamma, c^{*}\right)=\underline{\underline{c}}(p, A, \gamma) \Leftrightarrow c^{*}<\underline{\underline{c}}(p, A, \gamma) \\
&= \\
& c\left(p, A, \gamma, c^{*}\right)=\bar{c}(p, A, \gamma) \Leftrightarrow c^{*}>\bar{c}(p, A, \gamma)
\end{aligned}
$$

(32) shows that the norm-consistent interval is a symmetric interval around the Marshallian demand whose width, $2 \gamma$, depends on the strength of adherence to a norm. (33) shows that if the norm lies within the norm-consistent interval then the consumer adheres to the norm by consuming exactly the norm - even though it might differ from their Marshallian consumption. However if the norm lies below the norm-consistent interval the consumer adheres to the norm by consuming the lower bound of the interval, and conversely if the norm lies above the norm-consistent interval. The intuition is that the consumer is willing to adjust consumption away from the Marshallian level as long as the marginal loss of utility from deviating from the utility maximising level is lower than the marginal loss of utility from deviating from the norm; thereafter the consumer sticks at the bound of the interval.

\subsubsection{Stage 3}

In stage 3 we consider what could be equilibrium norms in our simple example of two groups of consumers. Consistent with the idea that norms just emerge from individual decisions and have no normative content, we use a very weak notion of equilibrium. So a norm is an equilibrium if it is the average consumption of all those who choose to adhere to it. We consider first the case where there is a single norm.

(i) Single Norm: There are two cases.

Case A:

$\gamma \leq 0.5\left(A_{H}-A_{L}\right) \Rightarrow \stackrel{=}{c}\left(p, A_{L}, \gamma\right)<\underline{\underline{c}}\left(p, A_{H}, \gamma\right) \Rightarrow c^{*}=\pi \underline{\bar{c}}\left(p, A_{L}, \gamma\right)+(1-\pi) \underline{\underline{c}}\left(p, A_{H}, \gamma\right)$

Case B: 
$\gamma>0.5\left(A_{H}-A_{L}\right) \Rightarrow \stackrel{=}{c}\left(p, A_{L}, \gamma\right)>\underline{\underline{c}}\left(p, A_{H}, \gamma\right) \Rightarrow c^{*} \in\left[\underline{\underline{c}}\left(p, A_{H}, \gamma\right), \stackrel{=}{c}\left(p, A_{L}, \gamma\right)\right]$

In Case A the norm-consistent intervals of the two groups do not overlap; so the only equilibrium norm is a weighted average of the upper-bound of the norm-consistent interval of the low-demand group and the lower-bound of the norm-consistent interval of the highdemand group, where the weights are the proportions of the two groups in the total population.

In Case B the norm-consistent intervals of the two groups do overlap, in which case any norm that lies in that interval is an equilibrium norm. Note that there are two possibilities: if $0.5\left(A_{H}-A_{L}\right)<\gamma<\left(A_{H}-A_{L}\right)$ then the interval $\left[\underline{\underline{c}}\left(p, A_{H}, \gamma\right), \stackrel{\bar{c}}{c}\left(p, A_{L}, \gamma\right)\right]$ is relatively narrow, and does not contain the Marshallian demands of either group; if $\gamma \geq\left(A_{H}-A_{L}\right)$ then the interval $\left[\underline{\underline{c}}\left(p, A_{H}, \gamma\right), \bar{c}\left(p, A_{L}, \gamma\right)\right]$ will contain the Marshallian demands of both groups.

(ii) Two Norms: Again we consider the two cases set out above.

In Case A the low demand group could adhere to any norm below the upper bound of its norm-consistent interval, with the opposite for the high demand group. In Case B the same is true as for Case A except that each group must be at least as well off adhering to its norm as to the norm of the other group, which is only an issue if at least one of the norms lies in the overlap area.

\subsubsection{Stage 2.}

Turning to stage 2, note that adhering to a norm reduces consumers' direct utility from consumption relative to just consuming according to their Marshallian demands. There are two elements to this loss. First if the consumer chooses to consume at the norm level, then there is the direct loss of utility from not consuming at the Marshallian level. Second, if the consumer chooses to consume at the boundary of her norm-consistent interval there is again the direct loss from not consuming at the Marshallian level plus the loss from not consuming at the norm level, measured by the strength of adherence to the norm. However, we now take account of the utility benefit of belonging to a group, $\Gamma$, the strength of desire for conformity. Consumers will adhere to the norm as long as $\Gamma$ exceeds the difference in utility between what consumers derive from adhering to the norm and what they would have got by going it alone and resorting to their Marshallian demands.

\section{$\underline{4.1 .4 \text { Stage } 1}$}

The above analysis explains why consumers may choose to adhere to consumption norms. We now turn to policy analysis. The government is concerned to maximise welfare defined by:

$$
\begin{aligned}
& W\left(c_{L}, c_{H} \mid c^{*}\right)=\pi\left[A_{L} c_{L}-0.5 c_{L}^{2}-q c_{L}-\gamma\left|c_{L}-c^{*}\right|+\Gamma\right]+ \\
& (1-\pi)\left[A_{H} c_{H}-0.5 c_{H}^{2}-q c_{H}-\gamma\left|c_{H}-c^{*}\right|+\Gamma\right]-\delta\left[\pi c_{L}+(1-\pi) c_{H}\right]
\end{aligned}
$$


There are essentially two 'distortions' in this model - the environmental externality and the fact that consumers are not consuming their Marshallian demands, though they are deriving benefits from adhering to a norm. Note that we have been assuming so far that the government is already dealing with the environmental externality by setting the usual Pigovian tax $\hat{t}=\delta$. So we are interested in what additional policies might be needed to deal with consumption norms. We consider the case where there is a single norm.

Note first that in Case A we see from (34a) that the equilibrium norm is sensitive to price, so it is possible to shift the norm closer to the level of demand that would arise under Marshallian demand, which will raise welfare while preserving the benefits of adhering to the norm. Now we know that low demand consumers are consuming more than their Marshallian demand by an amount $\gamma$ while high demand consumers are underconsuming by a similar amount. So it is straightforward to show that if the government imposes a tax

$$
\hat{\tau}=\gamma(2 \pi-1)
$$

this will align aggregate consumption with a norm with the Marshallian demand. If $\pi>0.5$, so low demand consumers predominate, then the optimal policy will be a tax to dampen the effects of their 'overconsumption'; if $\pi<0.5$, then high demand consumers predominate and the optimal policy is a subsidy to boost demand; finally if $\pi=0.5$ the two effects cancel out and there is nothing the government needs to do.

In Case B, it is clear from (34b) that the norm is not sensitive to modest changes in price. In this case the best the government can do to align individual decisions with the optimum is to ensure that the Marshallian demand lies in the overlap of the norm-consistent intervals of norms. This can be achieved by any tax/subsidy in the interval:

$$
\pi\left(A_{H}-A_{L}\right)-\gamma \leq \hat{\tau} \leq \gamma-(1-\pi)\left(A_{H}-A_{L}\right)
$$

In a wide range of circumstances this could be consistent with setting $\hat{\tau}=0$.

Putting together the Pigovian tax $\hat{t}=\delta$ and the tax to deal with social norms, $\hat{\tau}$ so the optimal policy will now be a combined tax $\hat{t}+\hat{\tau}$. Thus, for example, in Case $\mathrm{A}$, the overall policy will be to impose a tax $\hat{\tau}+\hat{t}=\gamma(2 \pi-1)+\delta$; note that if $\gamma>\delta$ and $0<\pi<(\gamma-\delta) / 2 \gamma$ this overall tax will be negative.

\subsection{Further Policy Analysis.}

In the previous section we assumed that the government was already implementing an optimal environmental tax, so this influenced the Marshallian demands of the two groups of consumers and their norm-consistent intervals of consumption. However a more interesting case arises if we assume that the government has not been imposing any environmental $\operatorname{tax}^{35}$. In Case A the imposition of the Pigovian tax will shift the norm-consistent intervals and the norm. However in Case B there are two more interesting possibilities. First, if $\delta$ is sufficiently small the Pigovian tax will shift the norm-consistent intervals, but if the existing

\footnotetext{
${ }^{35}$ Equivalently we could assume that the government has received revised and higher estimates of damage costs.
} 
norm remains in the overlap between the norm-consistent intervals of the high and low demand groups, consumers will continue to adhere to that norm, so the environmental policy instrument favoured by economists will have no effect on consumption or pollution.

Second, if, on the other hand, $\delta$ is sufficiently large it could shift down the overlapping interval of consumption so that it no longer contains the norm, in which case we assume that when the norm is no longer feasible consumers revert to their Marshallian demands. Of course these Marshallian demands with the Pigovian tax will be lower than they would be without the tax. Moreover, if $0.5\left(A_{H}-A_{L}\right)<\gamma<\left(A_{H}-A_{L}\right)$ low demand consumers will revert to Marshallian demands which are for sure lower than the lower bound of the interval $\left[\underline{\underline{c}}\left(p, A_{H}, \gamma\right), \bar{c}\left(p, A_{L}, \gamma\right)\right]$ and hence lower than the norm. On the other hand high demand consumers will revert to their Marshallian demands which are for sure higher than the upper bound of the interval $\left[\underline{\underline{c}}\left(p, A_{H}, \gamma\right), \bar{c}\left(p, A_{L}, \gamma\right)\right]$ and hence higher than the norm ${ }^{36}$. Could the latter effect outweigh the first two effects? The following example shows that there are parameter values for which this could be the case.

\section{Example 3:}

Suppose $M=1, A_{L}=30, A_{H}=40, \pi=0.1, q=10, \delta=3, \gamma=3$ and $\Gamma=15$.

The standard environmental economics story if consumers had no norms would be as follows:

(i) Prior to policy intervention $p_{0}=q=10$; Marshallian consumption of the two groups and total consumption are: $c_{L}=20, c_{H}=30, c=29$; consumer benefits are $B_{L}=200, B_{H}=450$ so aggregate consumer benefits are $B=0.1^{*}$ $B_{L}+0.9^{*} B_{H}=425$. Damage costs are 87 , so net welfare is: $425-87=338$.

(ii) After policy intervention the new price is $p_{1}=q+\delta==13$; so consumption of the two groups and total consumption are $c_{L}=17, c_{H}=27, c=26$; consumer benefits are $B_{L}=195.5, B_{H}=445.5$ so total consumer benefits are $B=0.1^{\star} B_{L}$ $+0.9^{\star} B_{H}=420.5$. Damage costs are 78 , so net welfare is 342.5 .

As usual in the conventional story, implementing environmental policy causes total consumption and hence direct consumer benefits to fall; the fall in consumption leads to lower pollution and lower damage costs, which more than offsets the reduction in direct consumer benefits.

Now allow for norms.

(iii) In the pre-policy equilibrium $\underline{c}_{H}=24, \quad \bar{c}_{L}=26$ so the interval in which the equilibrium norm must lie is $[24,26]$. Suppose the norm is $c^{*}=25$, to which both

\footnotetext{
${ }^{36}$ Of course if $\alpha>\left(A_{H}-A_{L}\right)$ then it is still possible that the norm lies between the two Marshallian demands and so the effects just described still apply
} 
groups adhere. Consumer benefits are: $B_{L}=187.5, B_{H}=437.5$, so total consumer benefits are $B=0.1^{\star} B_{L}+0.9^{\star} B_{H}=412.5$ and damage costs are 75 , so net welfare is $412.5-75=337.5$. Total consumer benefits are less than in the Marshallian equilibrium in (i), so if we allow for a fixed benefit of adhering to a norm of 15 then consumer benefits are 427.5, which is higher than consumer benefits of 425 in (i), which justifies consumers adhering to the norm. Welfare including the benefit of adhering to the norm is $427.5-75=352.5$

(iv) After the policy intervention, $\underline{c}_{H}=21, \bar{c}_{L}=23$ so the norm of $c^{*}=25$ is no longer in the norm-consistent interval. So the outcome is as in (ii) above.

So comparing (iii) and (iv) the implementation of conventional environmental policy, by making the previous norm infeasible, has caused total consumption to rise from 25 to 26, and total consumer benefits to rise from 412.5 to 420.5 ; the increase in consumption is driven by the fact that consumers are moving to their Marshallian demands, and although these are lower with the Pigovian tax in place than without it, because the majority of consumers are high demand consumers, the overall effect is to raise consumption. The rise in consumption causes pollution and hence environmental damage costs to rise from 75 to 78. Overall, welfare falls from 352.5 to 342.5 . This reduction in welfare is made up of three elements: direct consumer benefits have risen by 8 , environmental damage costs have worsened by 3 , but the benefit of adhering to a norm of 15 has been lost, so there is a net welfare loss of 10 .

So in this specific example, how conventional environmental policy as recommended by environmental economists affects the economy when there are consumption norms is the exact opposite of what is expected to happen with conventional Marshallian consumption. Of course this is just an example for a specific set of parameters and there will be other parameters for which the usual effects apply. This raises the question of how could policy makers know when conventional policies will work and when they will not work, and are there other policies that could be implemented when there are consumption norms. We discuss these issues in the final section.

\section{Section 5: Socially Directed Preferences - Altruism and Kantian Behaviour}

In Sections 3 and 4 we have considered socially embedded preferences where individual consumption behaviour is influenced by the consumption decisions of others, either through conspicuous consumption (a desire to "Keep up with the Joneses") or through consumption norms (a desire to conform to others' behaviour so as to feel a sense of community/solidarity with them).

In that analysis we maintained the traditional assumption that individuals maximised their individual well-being, $W$ - albeit adjusted to reflect the factors that generate the socially embedded nature of their preferences. In addition individual well-being was assumed to be affected by environmental damage caused by the aggregate/average consumption of various commodities. However, because we also assumed an atomless economy in which individuals rightly calculated that their consumption decisions would have no effect on the aggregate level of consumption, individuals did not take into account the fact that their own and other peoples' consumption was generating emissions that could cause damage both to 
themselves and others ${ }^{37}$. Consequently there is an uncorrected environmental externality and, in Sections 3 and 4, we have explored how the appropriate corrective policies - e.g. Pigovian taxes - are affected by the presence of socially embedded preferences.

In this part of the paper we drop the assumption of socially embedded preferences. In terms of the framework set out in Section 2 we are now assuming that $\theta=1$. So we are operating in the classical framework of environmental economics. As we showed in that section, given our other assumptions - e.g. an atomless economy, self-centred individuals who maximise their own well-being - the optimal policy is a standard Pigovian tax as given by equations (5) and (6).

As mentioned in Section 2 there are two components to a theory of socially directed preferences. The first involves dropping the assumption that individuals are self-centred and allow the possibility that individuals care about the well-being of others. In the case of Pure Altruism this means that the objective function driving individual behaviour is $(1+\alpha M) W$, where $\alpha \geq 0$ measures an individual's degree of altruism. But since this is formally equivalent to maximising $W$ both individual behaviour and the prescriptions for environmental policy are unaffected.

It follows that, for behaviour to be responsive to potential environmental consequences, we need to introduce the second component of the theory of socially-directed preferences and posit an alternative theory of behaviour in which individuals no longer just maximise individual utility (however constructed) but rather act in a different pro-social/moral fashion. There are a number of different accounts of such pro-social behaviour - which we review and then consider a more recent account by Daube and Ulph (2014). Here individuals deliberately act in a way that does not maximise individual utility but instead act "morally" by choosing a level of consumption that balances off the costs of individual utility forgone by not maximising this utility against the purely hypothetical moral gain that would arise - to themselves and others - if everyone were to make the same consumption choice as themselves. We assume that individuals might differ in this propensity to act morally - which we capture by the weight placed on the hypothetical moral gain.

We show that if individuals are willing to act in this way then:

(i) Individuals will adjust their consumption to take account of the impact of their decisions on themselves and others;

(ii) Altruism now matters in the sense that the greater the degree of altruism the greater the change in individual behaviour;

(iii) Nevertheless the optimal environmental policy is precisely the same as that which arises in the traditional analysis.

The intuition behind these results is as follows.

(i) Since individuals care about the moral rightness of their action they are willing to adjust their consumption towards the social optimum since they recognise that

\footnotetext{
${ }^{37}$ Such a calculation might be made particularly in the context of a global mixed pollutant such as $\mathrm{CO}_{2}$ emissions that is one of the drivers of climate change.
} 
hypothetically they and everyone else would be better off were everyone to follow this course of action. They recognise that they will pay a private cost in terms of reduced well-being by acting in this way, but are prepared to balance this off against the hypothetical moral gain and so are prepared to adjust behaviour to take account of its full impact on themselves and others.

(ii) Altruism now matters because the greater the weight that individuals place on the well-being of others the greater the hypothetical moral benefit from deviating from the conventional utility-maximising behaviour. However the degree of altruism has no effect on the cost of deviating from conventional utility-maximising behaviour.

(iii) Now when people behave morally the moral gain from such behaviour is purely hypothetical since any change in their behaviour will not affect the behaviour of others. So realised well-being is just the standard measure of individual wellbeing - albeit evaluated at a sub-optimal level of consumption of the dirty good. Since individuals may differ in the extent to which they act morally these differences in consumption behaviour introduce horizontal inequalities. So social welfare is below the optimum because (a) there is now horizontal inequality; (b) the level of pollution is sub-optimally high. However if the government sets the tax at the standard Pigovian optimum, then everyone will recognise that just maximising their individual utility will produce the social optimum, so, whatever their degree of morality everyone will consume the same amount of the dirty good - namely the social optimum - so setting this tax will eliminate all the horizontal inequality AND achieve the optimum amount of pollution.

So governments should not use the fact that individuals themselves care about the environment and are willing to adjust their behaviour as an excuse for not pursuing tough environmental policies.

\subsection{Brief Review of Literature}

There are a number of different accounts of both altruism and of why individuals might behave in what is called a pro-social fashion. For example, Andreoni (1988) showed that in large economies the share of the population making contributions to a public good tends to zero as the free-riding effect dominates. However, when the contribution to the public good also yields some private benefit to the individual, voluntary contributions can be consistent with standard economic models. Andreoni (1990) models the individual's utility not just as a function of the consumption of the private and public goods, but also of the individual's contribution to the public good itself. This is commonly referred to as the 'warm-glow' effect. This 'warm-glow' can be interpreted as a self-image gain from contributing to the public good.

While Andreoni makes no assumptions regarding the psychological cause of this 'warmglow' from the contribution to a public good, various other authors have developed more sophisticated models with regard to the underlying motivation ${ }^{38}$. These models usually work

\footnotetext{
${ }^{38}$ The term 'intrinsic motivation' is frequently used to describe the concept of warm-glow, where individuals derive a benefit from pro-social behaviour without consideration of its impact - see, for example, Clark et. al. (2003), Deci (1971) and Palfrey \& Prisbrey (1997). On the other hand a concern for self-image or reputation, as well as different types of altruism, can be thought of as extrinsic motivation since they do involve a consideration of the impact of the individual's choice.
} 
on the premise that individuals derive intrinsic value from a self-image desire or social norms. For example in the model of Bénabou and Tirole (2006) the 'reputational payoff' from contribution to a public good is a function of the belief others have regarding the type of consumer this individual is, while in Ellingsen and Johannesson (2008) the value of social approval depends on whether the individual himself approves of the person who approves him. In Nyborg, Howarth, and Brekke (2006) individuals are also motivated by a concern for self-image, which depends on their view of the total benefit a 'green' good yields to the population, as well as their view of what share of the population is choosing to consume the 'green' option. To some extent this also captures the idea of social norms or peer pressure. Furthermore, because what matters is the individual's perception of what others do, it is argued that policy makers may be able to influence this perception, for example through advertising. On the other hand, Brekke, Kverndokk, and Nyborg (2003) develop a model where individuals are able to make a more sophisticated calculation of the "morally ideal effort". This is achieved by evaluating the socially optimal contribution to a public good if they and everybody else were to make the same choice. The individual then derives self-image value depending on how close their contribution is to that socially optimal level.

The contributions to the literature on pro-social behaviour discussed so far essentially all assume no direct preferences for the welfare of others, and so are examples of what is called Impure Altruism, whereby individuals take account of only their own self-image which depends on their contribution to some public good. There is a more long-standing account of altruism whereby individuals may be motivated by a more direct concern about the welfare of others. Two main types of such altruism are Pure Altruism and Paternalistic Altruism. Pure Altruism captures the idea that an individual's utility may to some degree be a function of others' well-being/utility. Applications that use this type of altruism have often been based on smaller environments, such as the family ${ }^{39}$, where an individual's behaviour is likely to have a direct impact on those about whom he/she cares and so will be to some extent internalised. Paternalistic Altruism assumes an individual's utility is a function of a specific component of other peoples' utility ${ }^{40}$. In an environmental context, this component may be the damage experienced by others from the environmentally harmful good. While Impure Altruism only takes into account the individual's contribution to the externality, Paternalistic Altruism means that the individual is affected by others' experience of the externality, regardless of the individual's contribution.

All these types of altruism still assume that individuals maximise their utility when acting prosocially. Genuine Altruism as defined by Kennett (1980), on the other hand, requires that individuals' behaviour is driven by some function other than maximising their utility. Since this implies a deviation from 'rational' behaviour that economists usually assume, it is the most drastic form of altruism. In particular Johansson (1997) finds that with Genuine Altruism - modelled as a situation where individuals maximise a weighted sum of their own and others' utility - the optimal tax is lower than the standard level ${ }^{41}$. The socially optimal level of consumption is unchanged from the standard level as this type of altruism does not affect it, but the individual will demand this lower level of consumption due to the function

\footnotetext{
${ }^{39}$ For example Becker (1974), (1981)

${ }^{40}$ See Archibald and Donaldson (1976)

${ }^{41}$ In fact Johansson (1997) derives the socially optimal tax on an externality for all four types of altruism described above relative to the socially optimal tax level under standard behaviour. He shows that depending on the type of altruism analysed, the socially optimal tax on the externality can be higher, lower, or equal to the socially optimal tax without altruism.
} 
maximised and therefore the requirement on the tax level is reduced. If the weight in the maximisation were equal between the individual's utility and all others' utility, the tax rate would drop to zero.

The theory set out in Daube and Ulph (2014) and summarised here is an example of Genuine Altruism but yields very different conclusions, since we show that the optimal tax is the same as the standard Pigovian tax.

\section{2 A Theory of Moral Behaviour}

\subsubsection{Basic Assumptions}

In this sub-section we set out the basic ingredients of the theory, which relies on more specific functional forms than those employed in section 2.

Consider a population that comprises a continuum of potentially different types of individuals, indexed by $k, 0 \leq k \leq 1$. The distribution of types is given by the density function $f(k)>0, \quad 0 \leq k \leq 1$, where $\int_{0}^{1} f(k) d k=1^{42}$. The size/mass of the population is denoted by $M>0$.

Absent any considerations of altruism or morality, a typical individual has a utility function that depends on just two goods: the individual's consumption of a dirty good, $z$, and their expenditure on all other goods, $x$. The consumer price of this second good is normalised to 1 , and the consumer price of the dirty good is denoted by $p$. Assume that utility is linear in expenditure on all other goods ${ }^{43}$ but strictly increasing and concave in the consumption of the dirty good, so

$$
u(x, z)=x+\varphi(z)
$$

where $\varphi($.$) is a strictly increasing and strictly concave function { }^{44}$. It is assumed that, in the absence of any government transfers, each individual's income is $y>0$, so the utility arising from consuming an amount $z$ of the dirty good is

$$
u=\varphi(z)+y-p z
$$

Assume that each unit of the dirty good creates 1 unit of emissions so total emissions are $E=M \bar{z}$, where $\bar{z}=\int_{0}^{1} z_{k} f(k) d k$ is the average consumption of the dirty good in the population, and is unaffected by a change in the consumption, $z_{k}$ of any given individual or type of individual. This captures the central idea that motivates the analysis - that individuals correctly calculate that their consumption has no effect on aggregate emissions and so on any damage that they - and others - might suffer. Let $D=d(E)$ denote the individual

\footnotetext{
${ }^{42}$ For simplicity this heterogeneity in the population will play no role initially and everyone will be effectively identical

${ }^{43}$ This simplifying assumption is made in order to remove both effects from behaviour and any concerns about income inequality from the welfare analysis.

${ }^{44}$ Formally, we assume: $\varphi^{\prime}(z)>0 ; \quad \varphi^{\prime \prime}(z)<0$
} 
damage that everyone will suffer when total emissions are $E$. We assume that for all positive levels of emissions marginal damage is strictly positive and non-decreasing ${ }^{45}$.

In addition it is assumed throughout that the dirty good is produced by a perfectly competitive industry with constant unit costs of production $q>0$. So, as in the previous sections of the paper, the producer price of the dirty good is $q$. We allow the possibility that the government imposes a specific tax $t \geq 0$ on the dirty good, so its consumer price is $p=q+t$. Finally it is assumed that the tax revenues raised on the consumption of the dirty good are remitted to everyone via a lump-sum transfer $\sigma=t \bar{z}$, so individuals should also correctly recognise that this transfer is unaffected by their own consumption.

\subsubsection{Standard Theory}

Taking account of the damage caused by emissions, and the lump-sum transfer, a typical individual will take the average level of emissions, $\bar{z}$, as a constant and choose his/her consumption of the dirty good, $z$, to maximise well-being, $W$ - utility minus the cost of environmental damage:

$$
W=\varphi(z)+(y+t \bar{z})-p z-d(M \bar{z})=\varphi(z)+(y+t \bar{z})-(q+t) z-d(M \bar{z}) .
$$

Because individual concern about the public good nature of the problem posed by environmental externality is central to the rationale for moral behaviour, we assume that the weight attached to environmental damage is positive - i.e. $\delta>0$. However, to avoid unnecessary notation, in everything that follows we set $\delta=1$. This maximisation generates standard demand for the dirty good, $\tilde{z}(p)$, that is a strictly decreasing function of price alone and is characterised by

$$
\varphi^{\prime}(\tilde{z})=p=q+t
$$

Social welfare is assumed to be the sum of individual well-being and, recognising that the tax on the consumption of the dirty good is transferred to everyone via the lump-sum transfer, is given by

$$
S=M\left\langle\int_{0}^{1}\left\{\left[\varphi\left(z_{k}\right)+y-q z_{k}\right]\right\} f(k) d k-d\left(M \int_{0}^{1} z_{k} f(k) d k\right)\right\rangle
$$

Since, at this stage in the analysis, everyone has the same preferences, it is socially optimal to have everyone consume the same amount of the dirty good, $\hat{z}$. This is characterised by the condition that individual marginal benefit from an additional unit of consumption equals its full marginal social cost - the cost of production plus marginal damage. Formally

$$
\varphi^{\prime}(\hat{z})=q+M d^{\prime}(M \hat{z})
$$

\footnotetext{
${ }^{45}$ Formally , we assume, $\forall E>0 \quad d^{\prime}(E)>0 ; \quad d^{\prime \prime}(E) \geq 0$
} 
By comparing (41) and (43) it can be seen that the social optimum can be supported by individual behaviour through the imposition of the optimal Pigovian tax, $\hat{t}-$ equal to marginal damage at the optimum - on each unit of consumption of the dirty good.

$$
\hat{t}=M d^{\prime}(M \hat{z})
$$

This is just the analogue of the formula in (6) in Section 2, but for the special case where $\delta=1$ and the marginal utility of income is constant and equal to unity.

\section{$\underline{5.2 .3 \text { Introducing Pure Altruism }}$}

Suppose now that we allow the possibility that individuals care about not just their own wellbeing but that of everyone else. Since individuals are atomless, this essentially means that individuals place some weight on social welfare, $S$, as defined by (42). From (40) and (42) the well-being of a typical individual is now:

$$
W=\varphi(z)+(y+t \bar{z})-(q+t) z-d(M \bar{z})+\alpha S
$$

where $\alpha>0$ is the weight placed on the well-being of others - the degree of altruism - and, for simplicity, is assumed to be the same for everyone ${ }^{46}$.

In order to ensure that individual well-being is dominated by an individual's own direct wellbeing as given by (40) rather than the well-being of others, we impose the restriction that $\alpha M<1^{47}$.

When choosing his/her consumption of the dirty good, an individual will recognise that their decision will have no effect on the private consumption decisions, $z_{k}$ of everyone else, and so both components of social welfare that appear on the RHS of (42) - and so both social welfare, $S$, and average consumption of the dirty good, $\bar{z}$, will be treated as constants. Thus individual consumption decisions are again characterised by (42) and so are independent of the precise value of $\alpha$ within the range defined by the restriction $\alpha M<1$.

Social welfare is the sum of individual well-beings as given by (45) and so is now $(1+\alpha) S$. Maximising social welfare is therefore equivalent to maximising $S$ and so the optimal allocation of resources is also independent of the precise value of $\alpha$ within the range defined by the restriction $\alpha M<1$, and is characterised by having everyone consume the same amount, $\hat{z}$ of the dirty good, where $\hat{z}$ is given by (43). This optimum can again be supported by the optimal Pigovian tax, $\hat{t}$, as given by (44).

So we have the following:

Proposition 2: In an atomless economy, both individual behaviour and the socially optimal allocation of resources and supporting Pigovian tax rate are independent of the precise weight, $\alpha$, placed on altruism, subject to the restriction $\alpha M<1$.

\footnotetext{
${ }^{46}$ It can be shown that all the conclusions are unaffected if $\alpha$ varies across the population.

${ }^{47}$ See Johansson (1997) for a discussion of such a restriction.
} 


\section{2.4 Introducing Moral Behaviour}

Consider now the alternative calculus that individuals might make when choosing their consumption of the dirty good. Suppose that the government sets a tax $t, \quad 0 \leq t<\hat{t}$ that is sub-optimally low ${ }^{48}$, resulting in general over-consumption of the dirty good.

Suppose an individual considers choosing a level of consumption of the dirty good, $z$, which differs from $\tilde{z}(p)$, the level of consumption which maximises well-being as defined by (45) given the price $p=q+t$. The individual treats the lump-sum transfer, $\sigma=t \bar{z}$, the level of emissions and hence damages $d(M \bar{z})$, and the level of well-being accruing to everyone else, $S$, as constants. So, the individual will recognise that this choice of $z$ incurs a direct loss of personal well-being given by:

$$
L(z)=\{\varphi[\tilde{z}(p)]-p \tilde{z}(p)\}-[\varphi(z)-p z]
$$

On the other hand the individual will evaluate the morality of such an alternative choice of consumption in terms of its hypothetical moral benefit - the benefit that will accrue to both themselves and everyone else were everyone to choose the same level of consumption, $z$, rather than the utility-maximising choice, $\tilde{z}$. Taking account of this common choice on both the level of emissions - and hence damage - and the lump-sum transfer available to everyone, the hypothetical moral benefit from such a choice of $z$ is

$$
\begin{gathered}
H M B(z)=\{\varphi(z)-q z-d(M z)+\alpha M[\varphi(z)-q z-d(M z)]\}- \\
\{\varphi(\tilde{z})-q \tilde{z}-d(M \tilde{z})+\alpha M[\varphi(\tilde{z})-q \tilde{z}-d(M \tilde{z})]\}
\end{gathered}
$$

Assume that, in deciding what value of $z$ to choose, an individual maximizes a weighted sum of hypothetical moral benefit. So an individual chooses $z$ to maximise

$$
\mu H M B(z)-(1-\mu) L(z)
$$

where $\mu, \quad 0 \leq \mu \leq 1$ measures an individual's propensity to act morally, and is assumed to vary across individuals in the population. Substitute (46) and (47) into (48) and it follows that $z$ is chosen to maximise

$$
\varphi(z)-q z-[\tilde{k} d(M z)+(1-\tilde{k}) t]
$$

where

$$
\tilde{k}=\frac{\mu(1+\alpha M)}{1+\mu \alpha M} \text { and so } 0 \leq \tilde{k} \leq 1 ; \quad \tilde{k}=0 \Leftrightarrow \mu=0 ; \quad \tilde{k}=1 \Leftrightarrow \mu=1 \text {. }
$$

\footnotetext{
${ }^{48}$ The analysis that follows also applies if the tax is sub-optimally high.
} 
The parameter $\tilde{k}$ is said to measure the extent to which an individual is prepared to behave as a pure Kantian, and, given that the propensity to act morally, $\mu$, varies in the population, so too will the extent to which an individual is prepared to behave in a Kantian fashion.

The first-order condition characterising individual choice is

$$
\varphi^{\prime}(z)=q+\left[\tilde{k} M d^{\prime}(M z)+(1-\tilde{k}) t\right] .
$$

If we compare (51) with (41) and (43) we see that:

- If $\mu=0 \Rightarrow \tilde{k}=0$ then $z=\tilde{z}(q+t)$

- If $\mu=1 \Rightarrow \tilde{k}=1$ then $z=\hat{z}$

- If $0<\mu<1 \Rightarrow 0<\tilde{k}<1$ then $\hat{z}<z<\tilde{z}(q+t)$

So any level of individual consumption between the conventional self-interested utilitymaximising level and the social optimum can emerge as an outcome of this behaviour. This is illustrated in Figure 1.

Notice also that:

- If $\mu=0$ then $\tilde{k}=0$ irrespective of the value of $\alpha$

- If $\alpha=0$ then $\tilde{k}=\mu$

- If $\mu>0$ then $\tilde{k}$ is a strictly increasing function of $\alpha$, with $\tilde{k} \rightarrow 1$ as $\alpha \rightarrow \infty$.

So we have established the following:

\section{Proposition 3:}

(i) Any level of individual consumption between the conventional self-interested utility-maximising level and the social optimum can emerge as an outcome of this behaviour;

(ii) a propensity to act morally is both necessary and sufficient for individuals to adjust their behaviour away from the self-interested utility-maximising level towards the socially optimal level;

(iii) a degree of altruism is neither necessary nor sufficient for individuals to adjust their behaviour away from the self-interested utility-maximising level towards the socially optimal level;

(iv) nevertheless, if individuals have a propensity to act morally, then altruism matters and the more altruistic individuals are the more they move their consumption towards the social optimum.

It is important to recognise that in undertaking this calculus individuals make no assumption that anyone else will actually change their behaviour. Thus the moral benefit is purely hypothetical and never accrues to individuals. So realised individual well-being from any given choice of $z$ is given by (45) and consequently social welfare is just $(1+\alpha) S$ where $S$ is given by (42). 
In terms of this measure of welfare a given allocation arising from individual behaviour as described by (51) - will fall short of the full social optimum, for two reasons:

(a) if the government sets the wrong tax rate then aggregate emissions and damage may be sub-optimal

(b) since individuals differ in their propensity to act morally, consumption choices will differ and so there will be both horizontal and vertical inequality.

However it should be clear that if the government sets the optimal tax $t=\hat{t}$ then, irrespective of their propensity to act morally everyone will choose the same level of consumption, $\hat{z}$ and so the economy will achieve the social optimum, by both getting the optimal level of emissions and eliminating inequality. Thus we have:

Proposition 4: In a setting where individuals act morally the optimal tax rate is the standard Pigovian tax $\hat{t}$ that arises in the situation where individuals act in the conventional selfinterested fashion.

Two important policy conclusions from this analysis.

1. The fact that individuals may act morally and adjust their consumption of the dirty good towards the social optimum is not an argument for governments to set environmental policies that are too lax.

2. If governments try to adjust individual behaviour, then it is more effective to try to induce them to act morally rather than to promote altruism.

\section{Section 6: Implications for Empirical Testing, Policy Design and Future Research.}

In this paper we have summarised some of our recent research which has sought to build links between economics and sociology by studying consumer behaviour in a social context. Because we study interactions between the decisions of individual consumers it is natural to analyse these as Nash equilibria of the appropriate consumption games. We summarised our research in two broad forms of interactions between consumer preferences: socially embedded preferences with either competitive/conspicuous consumption or consumption norms, and socially directed preferences with altruism and moral behaviour. As we said in the Introduction the key question is whether such analysis generates interesting analytical results or implications for empirical analysis or policy. We believe the analysis does both.

In the case of competitive consumption we showed that there are cases, albeit very special, of utility functional forms and parameter values for which if all goods (which could include leisure) are have either conspicuous consumption externalities or environmental externalities (or both) there will be no market distortion, and there may be no need for taxes (or equivalent policies) to correct consumption. In the case of consumption norms we showed that if the differences between consumer groups with high and low demand for the norm good are not too large, then there may be a common norm which is completely insensitive to changes in prices, induced, say, by an environmental tax. Finally we showed that altruism may have no effect on people's consumption (and any resulting environmental damage) and what matters more is to persuade individuals to act more morally rather than to become more altruistic; even if that can be done, the optimal environmental tax is unaffected by the extent of such moral behaviour. 
A potential implication for the empirical analysis of consumption is that these forms of behaviour can have important effects on the responsiveness of consumption to prices, and so estimating demand functions in a conventional way may give misleading empirical inferences. For example, status goods may have very low price elasticities, so it is important to know whether an estimated low price elasticity for some commodity is due to underlying conventional preferences, or due to the role of that good as a status good. These two explanations can have quite different implications for policy design and welfare analysis, so it is important to not just estimate these price-elasticities but to test what factors drive consumer behaviour. Conventional environmental economic measures of revealed preferences or stated preferences, which draw on the assumption that consumers are egotists, may also be misleading if individuals are social animals.

Finally in terms of environmental policies, the standard environmental economics recommendation for Pigovian taxes may be unnecessary if the special cases of conspicuous consumption apply, or, in the case of social norms, either ineffective or even counterproductive. So there is a need to consider carefully what other policy approaches (for example, environmental information and education) might work to say shift consumption norms or induce more moral behaviour. This echoes findings of Hilton et al (2013) that the design of an environmental tax policy may depend critically on how the policy design also communicates social values, so there is a need to align financial and non-financial incentives.

All this suggests the need to continue to build links between the social sciences, particularly sociology and economics, and to consider what other aspects of consumption behaviour could be fruitfully studied using the kind of game theoretic approaches we have used in this paper. 


\section{Figure 1}

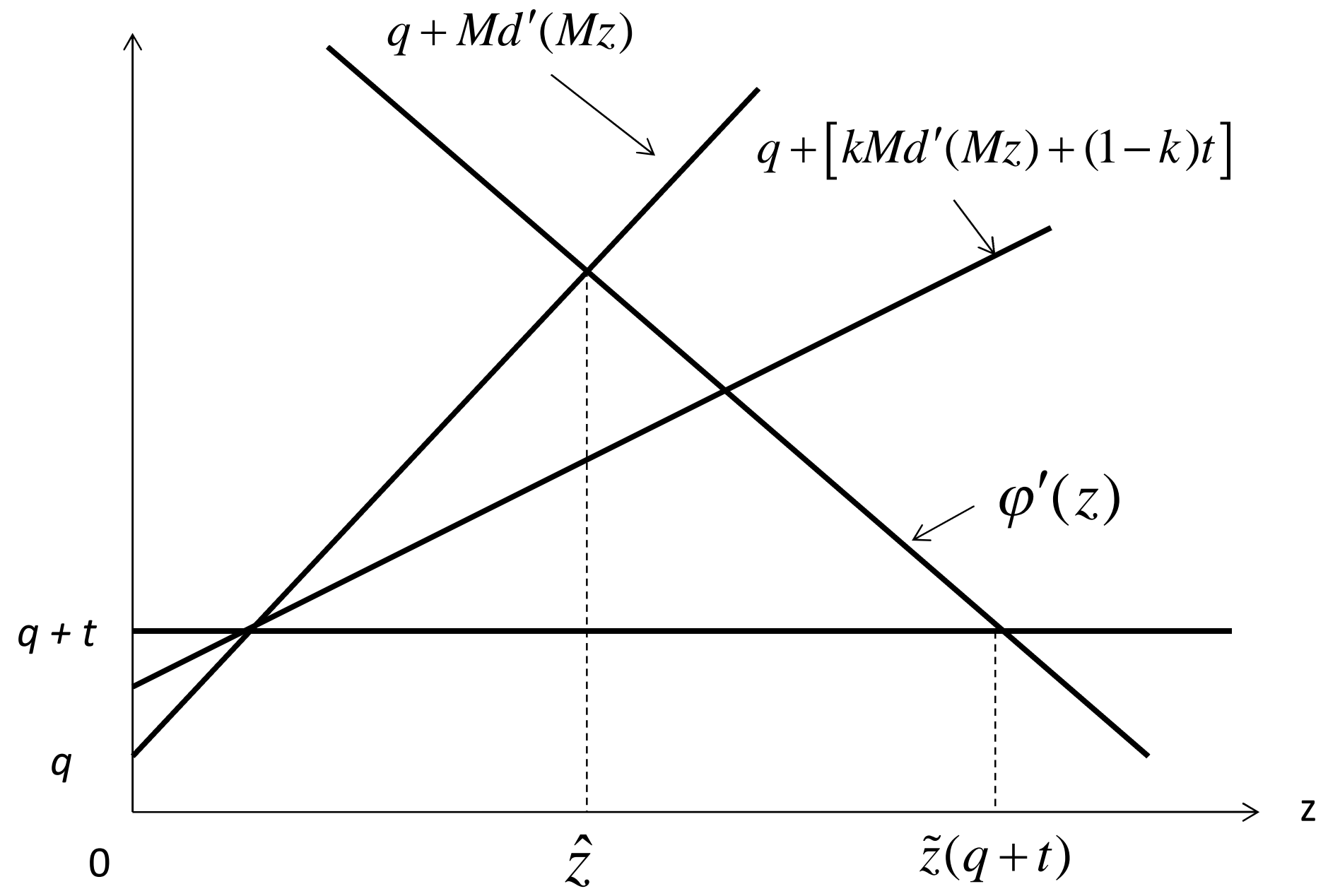




\section{References}

Akerlof, G. and R. Kranton (2000) "Economics and Identity", Quarterly Journal of Economics, 115(3): 715-753.

Allcott, H. (2011) "Social Norms and Energy Conservation" Journal of Public Economics, 95: 1082-1095.

Andreoni, J. (1988) "Privately Provided Public Goods in a Large Economy: The Limits of Altruism." Journal of Public Economics 35: 57-73.

Andreoni, J. (1990) "Impure Altruism and Donations to Public Goods: a Theory of Warm-Glow Giving.” The Economic Journal 100 (401): 464-477.

Archibald, G. and D. Donaldson (1976) "Non-Paternalism and the Basic Theorems of Welfare Economics." Canadian Journal of Economics 9 (3): 492-507.

Arrow, K. and P. Dasgupta (2009) "Conspicuous Consumption, Inconspicuous Leisure", The Economic Journal 119: F497-F516.

Bauman, Z. (1988) Freedom, University of Minnesota Press

Bauman, Z. (1990) Thinking Sociologically, Blackwell, Oxford.

Becker, G. (1974) "A Theory of Social Interactions." Edited by Steven N Durlauf and Lawrence E Blume. Journal of Political Economy 82 (6): 1063-1093.

Becker, G. (1981) "Altruism in the Family and Selfishness in the Market Place." Economica 48 (189): 1-15.

Bénabou, R. and J. Tirole (2006) "Incentives and Prosocial Behavior." The American Economic Review 96 (5): 1652-1678.

Bennett, T., M. Savage, E. Silva, A. Warde, M. Gayo-Cal, and D. Wright (2009) Culture, Class, Distinction, Routledge: London.

Bernheim, D. (1994) "A Theory of Conformity", Journal of Political Economy, 102(5): 841-877.

Bernheim, D. and A. Rangel (2007) "Towards Choice-Theoretic Foundations for Behavioral Welfare Economics", American Economic Review, 97(2): 464-470

Boskin, M. and Sheshinski, E., (1978) "Optimal Redistributive Taxation when Individual Welfare Depends upon Relative Income", Quarterly Journal of Economics, 92: 589-602.

Bourdieu, P. (1984) Distinction: A Social Critique of the Judgement of Taste, Routledge Kegan Paul, London 
Bourdieu, P. (1990) The Logic of Practice, Polity Press, Cambridge

Brekke, K., S.Kverndokk, and K. Nyborg (2003) "An Economic Model of Moral Motivation." Journal of Public Economics 87 (9-10): 1967-1983.

Bucholz, W., J. Falkinger and D. Rubbelke (2012) "Non-Governmental Public Norm Enforcement in Large Societies as a Two-Stage Game of Voluntary Public Good provision" ANU Working Paper in Economics and Econometrics, 566.

Camerer, C. G. Loewenstein and M. Rabin (2004) Behavioral Economics, Princeton University Press, Ann Arbor.

Clark, C., M. Kotchen, and M. Moore (2003) "Internal and External Influences on Pro-Environmental Behaviour: Participation in a Green Electricity Program", Journal of Environmental Psychology, 23, 237-246.

Copeland, B. and S. Taylor (2005) Trade and Environment: Theory and Evidence, Princeton University Press, Ann Arbor.

Cowan, R., W. Cowan and P. Swann (1997) "A Model of Demand with Interactions Among Consumers", International Journal of Industrial Organisation, 15: 711-732

Croson, R. and N. Treich (2014) "Behavioral Environmental Economics: Promises and Challenges" Environmental and Resource Economics, 58, 335-351.

Dasgupta, P. (2000) "Economic Progress and the Idea of Social Capital", in P. Dasgupta and I. Serageldin (eds.) Social Capital: A Multi-Faceted Perspective, The World Bank, Washington DC, 325-424.

Dasgupta, P. (2014) "Sustainability and the Determinants of Personal Consumption" in D. Southerton and A. Ulph (eds) Sustainable Consumption: Multi-Disciplinary Perspectives. Essays in Honour of Professor Sir Partha Dasgupta, Oxford University Press, Oxford, Ch 2.

Daube, M and D. Ulph (2014), "Moral Behaviour, Altruism and Environmental Policy", Environmental and Resource Economics, DOI 10.1007/s10640-014-9836-2.

Deci, E. (1971) "Effects of Externally Mediated Rewards on Intrinsic Motivation", Journal of Personality and Social Psychology, 18, 105-115.

Douglas, M. and B. Isherwood (1979) The World of Goods: Towards an Anthropology of Consumption, Penguin, Harmondsworth.

Easterlin, R. (1974) "Does Economic Growth Improve the Human Lot? Some Empirical Evidence" in P.David and M. Reder (eds.) Nations and Households in Economic Growth: Essays in Honor of Moses Abramowitz, Academic Press, New York. 
Easterlin,R. (2001) "Income and Happiness: Toward a Unified Theory", The Economic Journal, 111: 465-484

Ellingsen, T. and M. Johannesson (2008) "Pride and Prejudice: The Human Side of Incentive Theory." The American Economic Review 98 (3): 990-1008.

Endres, A (1997) "Negotiating a Climate Convention: the Role of Prices and Quantities", International Review of Law and Economics, 17(1), 147-156.

Endres, A and M. Finus (1998) Re-negotiation-proof Equilibria in a Bargaining Game Over Global Emissions: Does the Instrument Framework Matter?" in N. Hanley and M. Folmer (eds.) Game Theory and the Environment, Edward Elgar, Cheltenham, 135-164.

Endres, A. and M. Finus (1999) "International Environmental Agreements: How the Policy Instrument Affects Equilibrium Emissions and Welfare", Journal of Institutional and Theoretical Economics, 155(3), 527-550.

Endres, A. and M. Finus (2002) "Quptas May Beat Taxes in a Global Emissions Game", International Tax and Public Finance, 9, 687-707.

Endres, A. and C. Ohl (2002) 'Introducing 'Co-operative Push': How Inefficient Environmental Policy (Sometimes) Protects the Global Commons Better", Public Choice, 111, 285-302.

Endres, A. and C. Ohl (2003) "International Environmental Co-operation with Risk Aversion" International Journal of Sustainable Development, 6(3), 378-392.

Featherstone, M. (1987) "Lifestyle and Consumer Culture", Theory, Culture and Society, 4(1): 55-70.

Featherstone, M. (2007) Consumer Culture and Postmodernism, Sage, London.

Frank, R. (1985) Choosing the Right Pond: Human Behavior and the Quest for Status, Oxford University Press, New York.

Frey, B. and S. Meier (2004) "Social Comparisons and Pro-Social Behaviour: Testing Conditional Cooperation in a Field Experiment" American Economic Review , 94(5): 1717-1722.

Gerber, A. and T. Rogers (2009) "Descriptive Social Norms and Motivation to Vote: Everybody's voting and So Should You", Journal of Politics, 71: 1-14.

Gough, I., S. Abdallah, V. Johnson, J. Ryan-Collins, and C. Smith (2012) The Distribution of Total Greenhouse Gas Emissions by Households in the UK and Some Implications for Social Policy, CASE/152, STICERD, LSE 
Granovetter, M. (1978) "Threshold Models of Collective Behaviour", American Journal of Sociology, 83(6): 1420-1443.

Hargreaves-Heap, S. (2013) "Social Influences on Behaviour" in J. Mehta (ed.) Behavioural Economics in Competition and Consumer Policy, Report from ESRC Centre for Competition Policy, University of East Anglia.

Hargreaves-Heap, S. and D. Zizzo (2009) "The Value of Groups", American Economic Review, 99: 295-323.

IPCC (2014) Social, Economic and Ethical Concepts and Methods, Report of Working Group III.

Jenkins, R. (1996) Social Identity, Routledge, London.

Johansson, O. (1997) "Optimal Pigovian Taxes Under Altruism." Land Economics 73 (3): 297-308.

Kant, I. (1875) Grounding for the Metaphysics of Morals. Translated by Ellington J.W. 3rd ed. Hackett, Indianapolis.

Kennett, D. A. (1980) "Altruism and Economic Behavior, I: Developments in the Theory of Public and Private Redistribution." American Journal of Economics and Sociology 39 (2): 183-198.

Mailath, G. and L. Samuelson (2006) Repeated Games and Reputations: Long Term Relationships, Oxford University Press, New York.

Nyborg, K., R. B. Howarth, and K. A. Brekke (2006) "Green Consumers and Public Policy: On Socially Contingent Moral Motivation." Resource and Energy Economics 28 (4) (November): 351-366.

Palfrey, T. and J. Prisbrey (1997) "Anomalous Behavior in Public Goods Experiments: How Much and Why?", American Economic Review, 87(5), 829-846.

Putnam, R. (2000) Bowling Alone: The Collapse and Revival of American Community, Simon and Schuster, New York.

Rauscher, M. (1997) International Trade, Factor Movements and the Environment, Oxford University Press, Oxford.

Ritzer, G. (1993) The McDonaldisation of Society, Pine Fog Press, California.

Schor, J. (1998) The Overspent American, Basic Books, New York.

Schor, J. (2010) Plenitude: The New Economics of True Wealth, Penguin Press, New York.

Simmel, G. (1903) "The Metropolis and Mental Life", in G. Bridge and S. Watson (eds.), 2002, The Blackwell City Reader, Oxford and Malden, MA: Wiley-Blackwell. 
Sobel, J. (2005) "Interdependent Preferences and Reciprocity", Journal of Economic Literature, 43(2): 392-436.

Southerton, D. (2002), 'Boundaries of 'Us' and 'Them': class, mobility and identification in a new town', Sociology, 36(1): 171-193.

Southerton, D. and A. Ulph (2014) "Introduction" in D. Southerton and A. Ulph (eds) Sustainable Consumption: Multi-Disciplinary Perspectives. Essays in Honour of Professor Sir Partha Dasgupta, Oxford University Press, Oxford, Ch 1.

Tan, J. and F. Bolle (2007) "Team Competition and the Public Goods Game", Economics Letters, 96(1): 133-139.

Tetlock, P. (2003) "Thinking the Unthinkable: Sacred Values and Taboo Cognitions", Trends in Cognitive Science, 7: 320-324.

Tirole, J. (2002) "Rational Irrationality: Some Economics of Self Management", European Economic Review, 46: 633-655

Ulph, A. and D. Ulph (2007) "Climate Change - Environmental and Technology Policies in a Strategic Context" Environmental and Resource Economics, 37: 159180.

Ulph, A. and D. Ulph (2014) "Consumption Decisions When People Value Conformity" Working Paper, Department of Economics, University of Manchester.

Ulph, D. (2014), "Keeping up with the Jones: Who loses out?" mimeo, School of Economics \& Finance, University of St Andrews

Veblen, T. (1924) The Theory of the Leisure Class: An Economic Study of Institutions, George, Allen and Unwin, London

Warde, A. (1994) 'Consumption, identity-formation and uncertainty', Sociology, 28 (4): 877 - 898.

Warde, A. (1997) "Consumption, Taste and Social Change", in A. Warde (ed.) Consumption, Food and Taste: Culinary Antinomies and Commodity Culture, Sage, London: 7-21

Warde, A. and D. Southerton (2012) The Habits of Consumption, Open Access Book Series of the College of Advanced Studies, Helsinki.

Weber, M. (1980 [1920]) General Economic History, Transaction Books, New Brunswick. 